\title{
A two million year record of low-latitude aridity linked to continental weathering from the Maldives
}

Tereza Kunkelova', Simon J. A. Jung ${ }^{1}$, Erica S. de Leau', Nick Odling ${ }^{1}$, Alex L. Thomas ${ }^{1}$, Christian Betzler²,

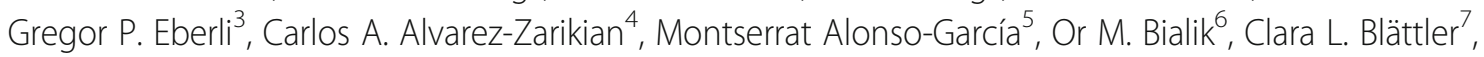
Junhua Adam Guo ${ }^{8}$, Sébastien Haffen ${ }^{9}$, Senay Horozal ${ }^{10}$, Anna Ling Hui Mee ${ }^{3}$, Mayuri Inoue ${ }^{11}$, Luigi Jovane ${ }^{12}$, Luca Lanci $^{13}$, Juan Carlos Laya ${ }^{14}$, Thomas Lüdmann ${ }^{2}$, Nagender N. Bejugam ${ }^{15}$, Masatoshi Nakakuni ${ }^{16}$, Kaoru Niino ${ }^{17}$, Loren M. Petruny ${ }^{18}$, Santi D. Pratiwi ${ }^{19}$, John J. G. Reijmer ${ }^{20}$, Jesús Reolid ${ }^{2}$, Angela L. Slagle ${ }^{21}$, Craig R. Sloss ${ }^{22}$, Xiang Su ${ }^{25}$, Peter K. Swart ${ }^{3}$, James D. Wright ${ }^{24}$, Zhengquan Yao ${ }^{23}$, Jeremy R. Young ${ }^{26}$, Sebastian Lindhorst ${ }^{2}$, Stephanie Stainbank ${ }^{27}$, Andres Rueggeberg ${ }^{27}$, Silvia Spezzaferri ${ }^{27}$, Igor Carrasqueira ${ }^{12}$, Siyao Yu $^{24}$ and Dick Kroon ${ }^{1 *}$

\begin{abstract}
Indian-Asian monsoon has oscillated between warm/wet interglacial periods and cool/dry glacial periods with periodicities closely linked to variations in Earth's orbital parameters. However, processes that control wet versus dry, i.e. aridity cyclical periods on the orbital time-scale in the low latitudes of the Indian-Asian continent remain poorly understood because records over millions of years are scarce. The sedimentary record from International Ocean Discovery Program (IODP) Expedition 359 provides a well-preserved, high-resolution, continuous archive of lithogenic input from the Maldives reflecting on low-latitude aridity cycles. Variability within the lithogenic component of sedimentary deposits of the Maldives results from changes in monsoon-controlled sedimentary sources. Here, we present X-ray fluorescence (XRF) core-scanning results from IODP Site U1467 for the past two million years, allowing full investigation of orbital periodicities. We specifically use the Fe/K as a terrestrial climate proxy reflecting on wet versus dry conditions in the source areas of the Indian-Asian landmass, or from further afield. The Fe/K record shows orbitally forced cycles reflecting on changes in the relative importance of aeolian (stronger winter monsoon) during glacial periods versus fluvial supply (stronger summer monsoon) during interglacial periods. For our chronology, we tuned the Fe/K cycles to precessional insolation changes, linking Fe/K maxima/minima to insolation minima/maxima with zero phase lag. Wavelet and spectral analyses of the Fe/K record show increased dominance of the $100 \mathrm{kyr}$ cycles after the Mid Pleistocene Transition (MPT) at $1.25 \mathrm{Ma}$ in tandem with the global ice volume benthic $\delta^{18} \mathrm{O}$ data (LR04 record). In contrast to the LR04 record, the Fe/K profile resolves 100-kyr-like cycles around the 130 kyr frequency band in the interval from 1.25 to 2 million years. These 100-kyr-like cycles likely form by bundling of two or three obliquity cycles, indicating that low-latitude Indian-Asian climate variability reflects on increased tilt sensitivity to regional eccentricity insolation changes (pacing tilt cycles) prior to the MPT. The implication of appearance of the $100 \mathrm{kyr}$ cycles in the LRO4 and the Fe/K records since the MPT suggests strengthening of a climate link between the low and high latitudes during this period of climate transition.
\end{abstract}

Keywords: Maldives, IODP Exp 359, Non-destructive core scanning, Composition of lithogenic fraction, Orbital cycles, Indian-Asian history of aridity, Mid Pleistocene transition

\footnotetext{
* Correspondence: dick.kroon@ed.ac.uk

${ }^{1}$ School of GeoSciences, Grant Institute, University of Edinburgh, The King's

Buildings, West Mains Road, Edinburgh EH9 3JW, UK

Full list of author information is available at the end of the article
} 


\section{Introduction}

Over the last two million years (Myr), the Earth's climate has oscillated between cold and warm periods driven by semi-periodic changes of the Earth's orbit around the Sun. These changes forced waxing and waning of ice sheets accompanied by global changes in sea surface temperatures (SSTs), sea level, and extent of deserts in low latitudes (Clemens et al. 1996). The general trend of Earth's climate shows a shift towards colder conditions, marked by a stepped increase in the amplitude of glacial ice volume across the Mid Pleistocene Transition (MPT; for an overview, see Head and Gibbard (2015), although they used the term Early-Middle Pleistocene Transition).

The MPT, which began at about $1.25 \mathrm{Ma}$ and ended about 0.7 Ma (Fig. 1), is characterised by a change in glacial-interglacial cycles from a dominantly $41 \mathrm{kyr}$ to a $100 \mathrm{kyr}$ periodicity (Berger and Jansen 1994; Mudelsee and Stattegger 1997). However, the emergence of the $100 \mathrm{kyr}$ cycles is still a matter of debate and it is unclear why the Earth's climate system started to respond non-linearly to orbital forcing (Maslin and Brierley
2015). Elderfield et al. (2012) reported a rapid increase in ice volume during glacial stage 22 at about $0.9 \mathrm{Ma}$, and during following glacial stages. Whereas temperatures decreased, and ice volume increased during glacial periods post-MPT, ice volume and temperature maxima remained relatively constant during the interglacial periods for mid and low latitudes (Herbert et al. 2010; Rodrigues et al. 2017).

African terrestrial climate (wet-dry or aridity cycles) records from International Ocean Discovery Program (IODP) drill sites around Africa similarly show a prominent switch in dominance from the $41 \mathrm{kyr}$ to the $100 \mathrm{kyr}$ periodicities during the MPT (deMenocal et al. 2000; Grant et al. 2017). However, to date, there has been a conspicuous lack of long-term aridity records from the Maldives. This area is situated in a particularly desirable location as it receives large amounts of windblown dust derived from the surrounding Indian-Asian landmass. Further, small amounts of fluvial material are derived from nearby India carried by currents originating in the Arabian Sea or Bay of Bengal. Therefore, a

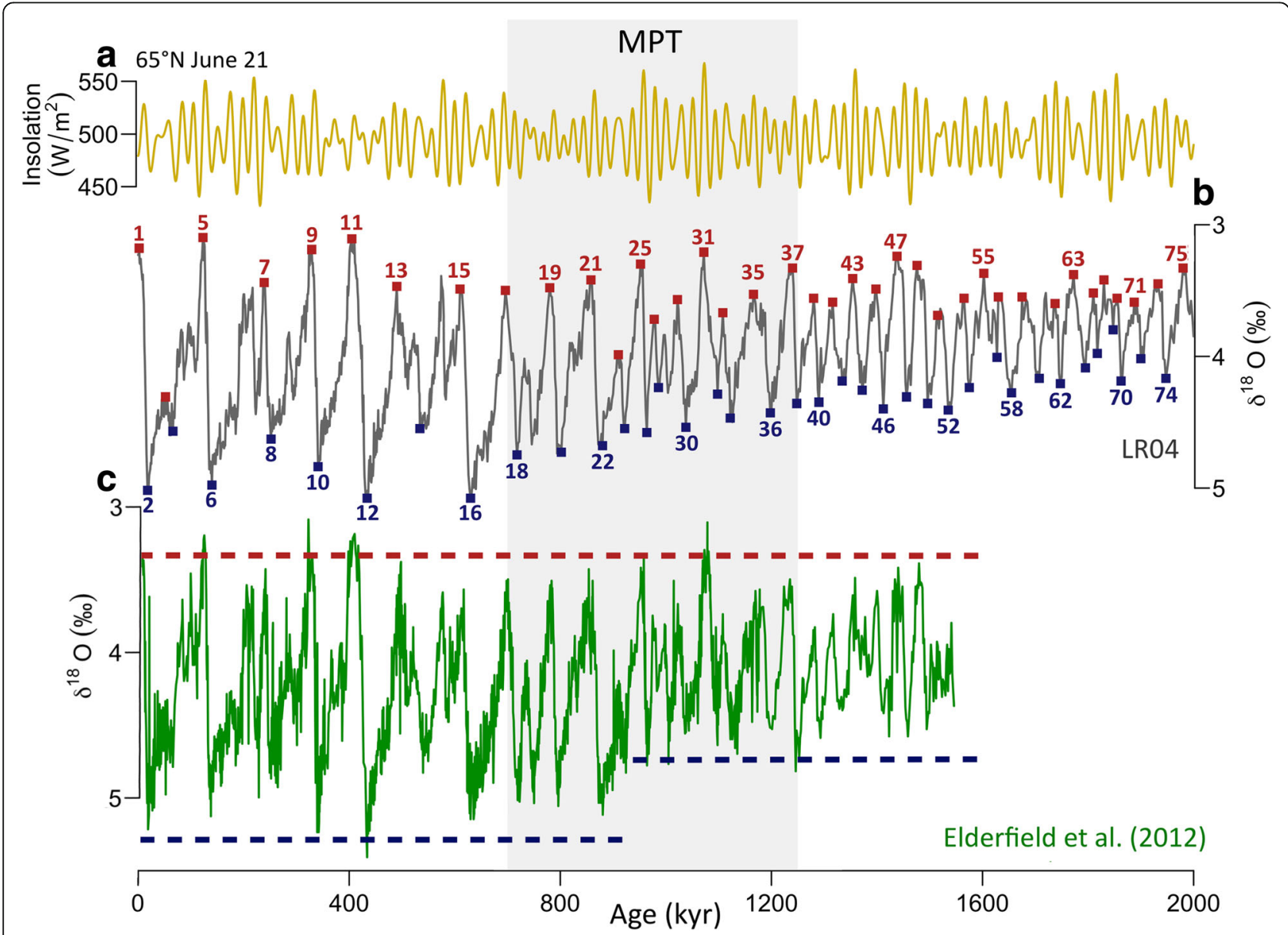

Fig. 1 Earth's climate variability in the last two Myr. a 65 N 21st June insolation. b Global ice volume benthic LR04 stack (Lisiecki and Raymo 2005). c Global ice volume stack by Elderfield et al. (2012). Note the sudden increase in ice volume at stage 22 in the Mid Pleistocene Transition (MPT) 
long-term lithogenic input record from the Maldives, used as a proxy record for aridity linked to continental weathering at source areas, provides a unique opportunity to investigate the Indian-Asian monsoon response to the major global climate transition (MPT) over the last two million years. IODP Expedition 359 (Betzler et al. 2017a) drilled several sites in the carbonate platform of the Maldives archipelago (Fig. 2). The sedimentary record of Site U1467, drilled in the drift sediments associated with the atolls, provides a well-preserved, high-resolution, continuous archive of lithogenic input into the southern end of the eastern Arabian Sea.

We use X-ray fluorescence (XRF) core-scanning records of lithogenic related element fluorescence intensities from IODP Site U1467 to evaluate influence of orbital cycles on variability in Indian-Asian terrestrial climate related to monsoon activity over the last two million years. In this study, we use $\mathrm{Fe} / \mathrm{K}$ as a proxy of aridity in marine sediments from the Maldives, where high ratios indicate humid conditions and low values dry conditions. The changes from high to low ratios reflect wet-dry (aridity) changes in source areas, predominantly on the Indian-Asian landmass; however, African sources cannot be completely excluded. Fe/K proxy has been successfully applied in marine sediments offshore Africa (Mulitza et al. 2008; Govin et al. 2012; Simon et al. 2016; Ziegler et al. 2013). The two million year $\mathrm{Fe} / \mathrm{K}$ record from Site U1467 allows us to evaluate influence of regional orbital insolation and high-latitude ice volume changes on low-latitude 'wet-dry' cycles across the MPT.
Specifically, we document influence of the 100-kyr-like cycles on amplitude of change in wet-dry (aridity) cycles prior to the MPT. Tropical sea surface temperature records (Liu et al. 2008) and tropical Pacific grain size (wind strength) records (Yu et al. 2018) show presence of late Pliocene to early Pleistocene 100-kyr-like cycles formed by bundling of two/three obliquity cycles prior to the MPT. Such late Pliocene/early Pleistocene 100-kyr-like cycles have not been previously reported using wet-dry cycles from bore holes in the Maldives.

\section{Lithogenic input in sediments of the Maldives}

The sedimentary deposits in the Maldives contain lithogenic components derived from a mixture of sediment sources. While dust grains form the largest component of the detrital sediments, fluvial supplied material form the minor component. Today, the Maldives area is strongly affected by the seasonally reversing Indian-Asian monsoon system (Fig. 2): south-western monsoon winds dominate between April and November, whereas north-eastern monsoon winds dominate between December and March (Wyrtki 1973). The summer monsoon brings strong precipitation over the Indian-Asian landmass, and high dust flux into the western Arabian Sea (McDonald 1938; Prospero 1981; Middleton 1986; Nair et al. 1989). The winter winds bring cold air laden with dust over the Arabian Sea. Modern satellite data show the aerosol distribution in the Arabian Sea and the Maldives area, confirming the seasonal evolution of the dust plumes in 2017 (Fig. 3). While the summer dust plume originating from the north-western

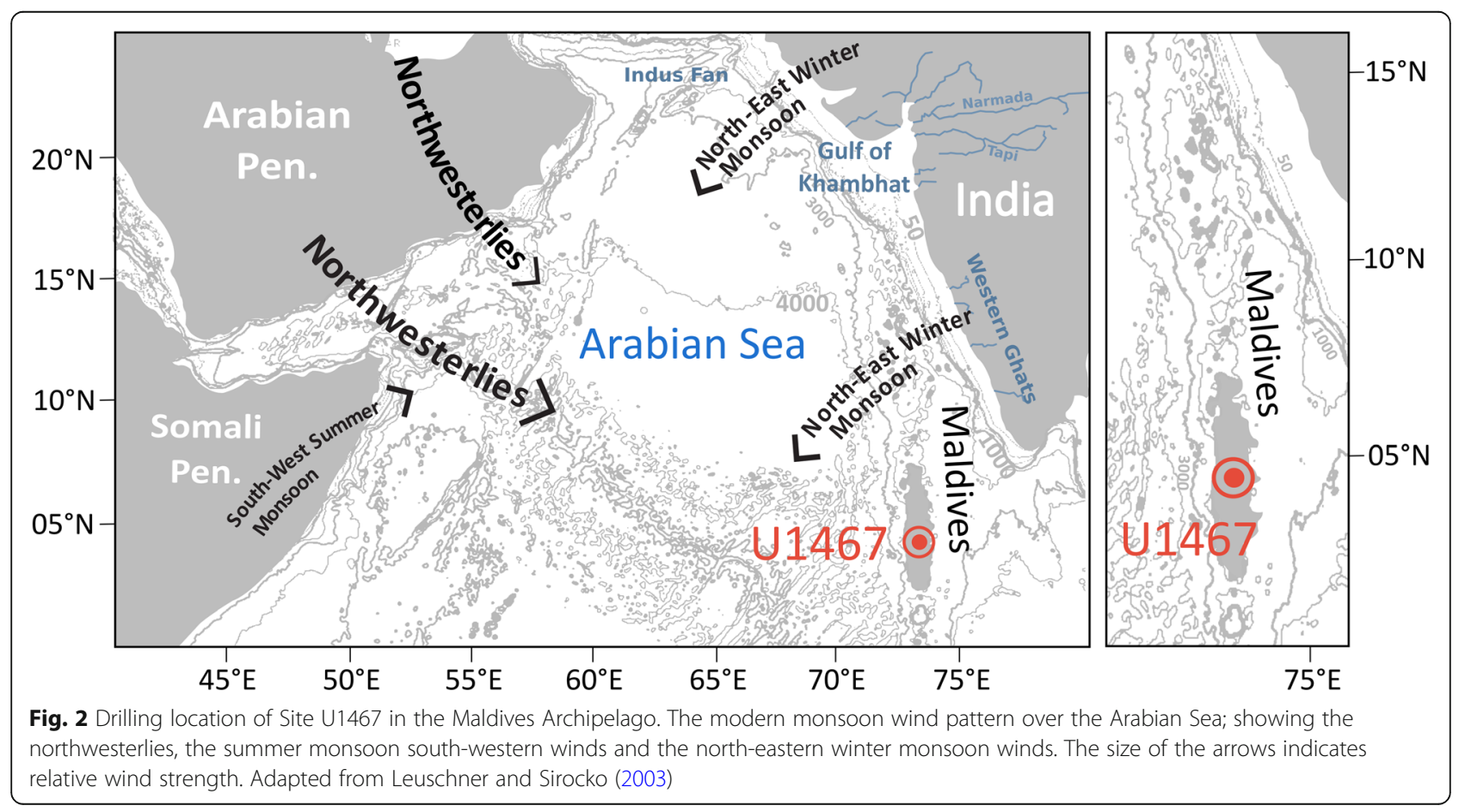



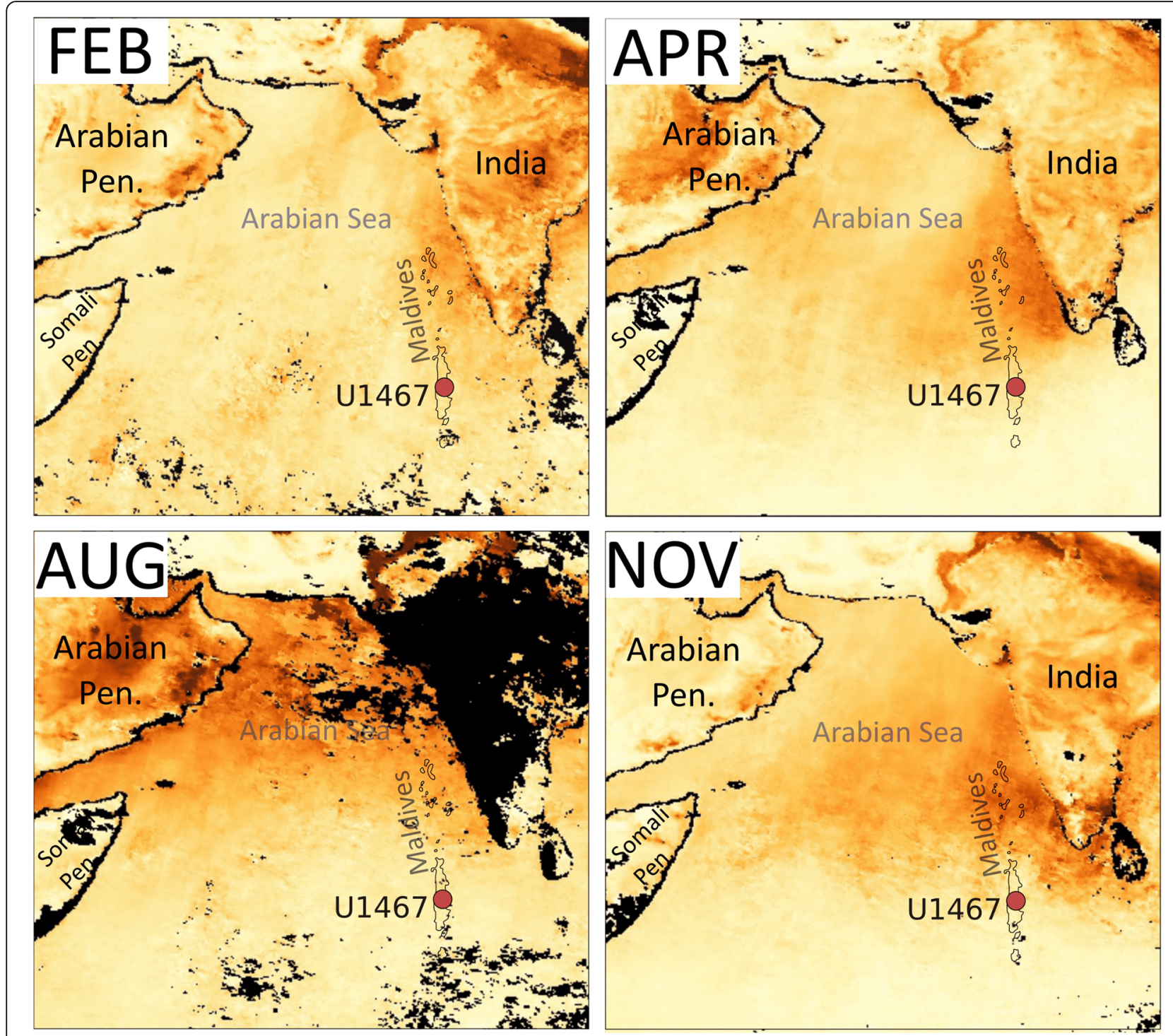

Fig. 3 A compilation of aerosol distribution in the northern Indian Ocean during selected months during 2017 (Aerosol Optical Thickness, NASA, n.d.). Note that the winter dust plume reaches the Maldives

Arabian Sea scarcely extends into the eastern Arabian Sea and the Maldives, the winter dust plume originating from the Indian-Asian landmass certainly reaches the Maldives.

Outflow of riverine material is the main source of lithogenic flux in the eastern Arabian Sea (Milliman et al. 1984). Fluvial-derived material in the Arabian Sea is deposited in areas close to river deltas, e.g. the mouth of the Indus, Narmada and Tapi rivers draining into the Gulf of Khambhat and 16 small rivers draining the Western Ghats (Ivanochko et al. 2005). Due to its bathymetric isolation, minor quantities of riverine material get transported by currents to the Maldives (Kolla et al. (1981). While some lithogenic material from the Arabian Sea leaks southwards to the Maldives, north-eastern winter currents also carry small quantities of fine grained fluvial-derived material from the Bay of Bengal south and westwards to the Maldives (Kolla et al. 1981).

In summary, lithogenic material deposited in the Maldives is a mixture of dominantly aeolian transported grains from far afield and small amounts of riverine material from the Indian continent and Bay of Bengal. The new Site U1467 drilled in the Maldives Inner Sea during IODP Expedition 359 is ideal for documenting relative importance of wind-borne dust (winter monsoon) and small fraction of fluvial-derived material (summer monsoon) from India through time.

\section{Methods/Experimental}

The IODP Expedition 359 cored four holes at Site U1467 in the Maldives archipelago, southwest of India 
$\left(4^{\circ} 51^{\prime} \mathrm{N}, 73^{\circ} 17^{\prime} \mathrm{E}\right)$, that is an isolated, partly drowned tropical carbonate platform (Betzler et al. 2016, 2017a). The inner-atoll Site U1467 is a sedimentary drift sequence at a water depth of $487.4 \mathrm{~m}$ (Fig. 2). The sequence is continuous and preserves the variability of the lithogenic fraction, recording a regional history of aridity linked to the hydrological cycle. Betzler et al. (2017a) noted cyclical colour changes in the sediment cores and linked these to the primary orbital cycles. The nannofossil and planktonic foraminiferal records confirm that the Plio-Pleistocene record is continuous and complete, with sedimentation rates of about $3 \mathrm{~cm}$ per thousand years (kyr) (Betzler et al., 2017b). A shipboard composite depth record was established (Betzler et al. 2017b) and correlations between the various bore holes were accomplished using standard IODP procedures (Correlator software version 2.01.1.). High-resolution compositing was based on sediment lightness $\left(\mathrm{L}^{*}\right)$ data in Holes U1467A-U1467D. However, the shipboard splice was adjusted after the cruise based on newly produced XRF core-scanning data at the IODP core store repository in Texas. The newly produced XRF core-scanning data are considered to be more accurate than the shipboard lightness $\left(\mathrm{L}^{*}\right)$ data. Individual Fe content records in the various boreholes are shown in Fig. 4, including the new composite Fe content record against the new composite depth (mcd $=$ meters composite depth). The new splice data, including the splice intervals, core offsets, and tie points between each borehole, are archived on the IODP LIMS Database (http://iodp.tamu.edu/database/).

\section{Scanning electron microscope}

The lithogenic component of the sediment was analysed with a Carl Zeiss SIGMA HD VP field emission scanning electron microscope (SEM) at the University of Edinburgh. We analysed eight selected samples from glacial and interglacial intervals. Samples were treated with 3\% ethanoic acid to remove calcite and aragonite from the samples. Remaining suspensions were centrifuged at $2500 \mathrm{rpm}$ for $30 \mathrm{~min}$ and the residue pellet rinsed with deionised water. This leaching procedure was repeated to maximise carbonate removal. The residue pellet was then re-suspended in a few drops of ethanol and transferred onto an SEM stub. Energy dispersive analysis, calibrated against a Co metal standard, was used to establish the chemical composition of the residue grains.

\section{X-ray fluorescence}

Non-destructive X-ray fluorescence (XRF) scans were measured at the Ocean Drilling and Sustainable Earth Science (ODASES) XRF scanning facility at the IODP Gulf Coast Repository (GCR) in Texas A\&M University using a third-generation AvaaTech XRF scanner configured to analyse split sediment core halves for elements between $\mathrm{Mg}$ and $\mathrm{U}$ in the periodic table (Lyle and Backman 2013). Data were acquired with a Canberra X-PIPS silicon drift detector (SDD) with $150 \mathrm{eV}$ X-ray resolution at $5.9 \mathrm{keV}$ and a Canberra Digital Spectrum Analyser model DAS 1000. The X-ray source was an Oxford Instruments $100 \mathrm{~W}$ Neptune X-ray tube with a rhodium (Rh) target. Raw spectral data were processed using the Canberra

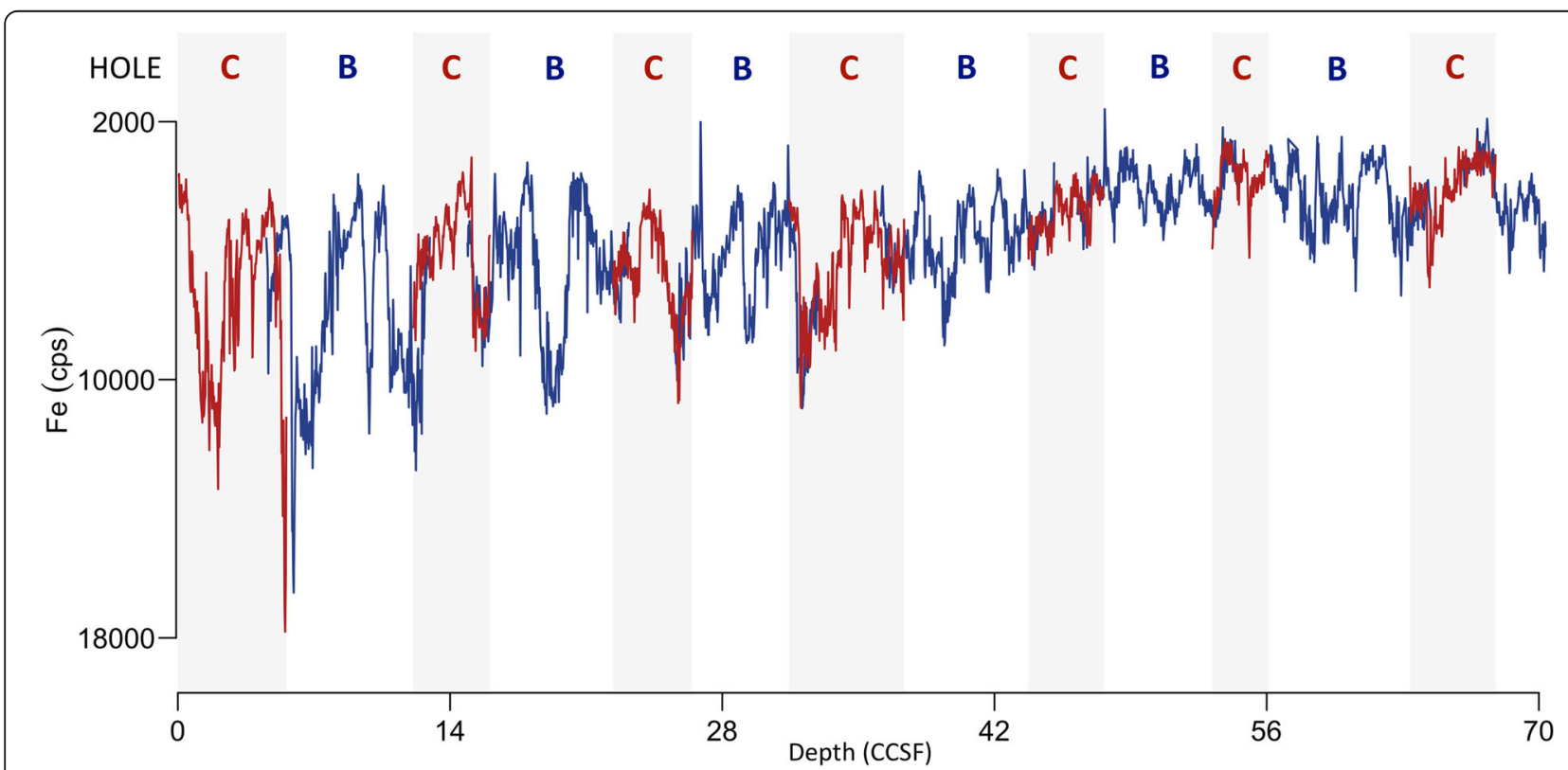

Fig. 4 The composite of Fe intensity (cps = counts per second) record comprised of segments from Holes B and C; CCSF core composite depth below sea floor 
WINAXIL software package to produce elemental intensity data. The dual slit system was set to provide down-core spatial resolution of $10 \mathrm{~mm}$ and cross-core spatial resolution of $12 \mathrm{~mm}$. The system was set to perform two consecutive runs of the same section, the first one at $9 \mathrm{kV}, 0.25 \mathrm{~mA}$ and $6 \mathrm{~s}$, and the second one at $30 \mathrm{kV}, 1.25 \mathrm{~mA}$ and $6 \mathrm{~s}$. The first scan provides data for the elements $\mathrm{Mg}, \mathrm{Al}, \mathrm{Ba}, \mathrm{Ca}, \mathrm{Cl}, \mathrm{Cr}$, $\mathrm{Fe}, \mathrm{K}, \mathrm{Mn}, \mathrm{P}, \mathrm{S}, \mathrm{SI}, \mathrm{Rh}$ and $\mathrm{Ti}$, and the second for $\mathrm{Bi}$, $\mathrm{Cu}, \mathrm{Br}, \mathrm{Fe}, \mathrm{Ga} \mathrm{Nb}, \mathrm{Ni}, \mathrm{Mo}, \mathrm{Pb}, \mathrm{Rb}, \mathrm{Sr}, \mathrm{Y}, \mathrm{Zn}$ and $\mathrm{Zr}$. Each core section was removed from refrigeration at least $2 \mathrm{~h}$ before scanning and scraped to clean and smooth the core surface. The split core surface was covered with $4 \mu \mathrm{m}$ thick Ultralene plastic film to prevent contamination of the X-ray detector. Measurements were taken at $3 \mathrm{~cm}$ intervals whenever possible. Because measurements cannot be performed if the sediment presents cracks or uneven surface, some measurements were skipped or shifted to the nearest suitable area.

Samples from a selected interval (Cores 359-U1467C$4 \mathrm{H}$ to $-6 \mathrm{H}$ ) were analysed using both the AvaaTech XRF core scanner at Texas A\&M and a conventional XRF instrument at the University of Edinburgh. For these $1 \mathrm{~g}$ aliquots of core material were ground in an agate mortar and pestle and then pressed into $1 \mathrm{~cm}$ diameter pellets using a pellet press operating at a pressure of $2 \mathrm{t} / \mathrm{cm}^{2}$. Pellets were analysed on a Philips PW2404 XRF spectrometer with a Rh-anode X-ray tube. Corrections for matrix effects on the intensities for major element lines were made using theoretical alpha coefficients calculated using Philips software (Reynolds 1963). Intensities of the longer-wavelength trace element lines were corrected for matrix effects using alpha coefficients based on major element concentrations. For other trace elements, matrix corrections were applied using the $\mathrm{Rh} \mathrm{K}$ alpha Compton scatter line as an internal standard. Line overlap corrections were applied using synthetic standards. The spectrometer was calibrated with 15 USGS and CRPG standards using the values given in Govindaraju (1994). Data derived from this procedure are reported both as raw count rates (for direct comparison with the AvaaTech XRF core scanner at Texas A\&M) and as wt.\% oxides for major elements and ppm for trace elements for more routine data presentation. The pellets, analysed for major element and trace element composition at Edinburgh, were subsequently sent to Texas A\&M University for analysis using the same AvaaTech XRF core scanner. This procedure facilitated direct comparison of the scanned results from the two instruments, evaluation of uncertainties in the XRF scanning counts, and calibration of the AvaaTech XRF output for individual elements where appropriate. All data will be also archived in Pangaea.

To evaluate the reliability of Fe intensities scanned with XRF core scanner, the same subset of core (Cores
$359-\mathrm{U} 1467 \mathrm{C}-4 \mathrm{H}$ to $-6 \mathrm{H})$ was selected and sampled at a $3 \mathrm{~cm}$ interval. This enabled a comparison between the 'wet' dataset acquired by XRF core scanner and the fully quantitative 'dry' dataset by conventional XRF. The samples were finely ground and made into pellets for analysis by wavelength dispersive XRF at the University of Edinburgh. Pellets were analysed for a range of major and trace elements. Plot of Fe content from conventional XRF of dry ground pellets versus the equivalent position of Fe intensities in the 'wet' core by XRF core scanner shows a reasonable correlation coefficient $\left(R^{2}=0.7\right)$. Regression of this relationship allows for conversion of the 'wet' core scanner Fe count rates into $\mathrm{Fe}$ wt.\%. We calculated flux of $\mathrm{Fe}\left(\mathrm{gm}^{-2} \mathrm{year}^{-1}\right)$ by multiplying linear sedimentation rate by dry bulk density (Betzler et al. 2017b) and Fe intensities (cps).

\section{Spectral and wavelet analyses}

Multitaper method (MTM) spectral analysis, data filtering, coherency and wavelet analysis with a Morlet wave transform were performed on the $\mathrm{Fe}$ intensity, $\mathrm{Fe} / \mathrm{K}$ records and for comparison the LR04 $\delta^{18} \mathrm{O}$ stack record (Lisiecki and Raymo 2005). The MTM spectral analysis was performed using the Astrochron package by Meyers (2014) in R, data were smoothed using a three-point moving average (excluding LR04), normalised and detrended. Analyseries 2.0.8. (Paillard et al. 1996) was used to perform filtering and coherency analysis; frequency (f) and bandwidth (ban) parameters used for data filtering were eccentricity $(f=0.0105$, ban $=0.001)$, obliquity $(f=0.024$, ban $=0.03)$ and precession $(f=0.048$, ban $=0.006$ ). Wavelet analysis was produced using Past software (Hammer et al. 2001).

\section{Results}

\section{Scanning electron microscope}

Primary observations by SEM show the presence of dust particles. The dust particles are easily recognised because of their abraded surfaces resulting from particle-particle collisions during aeolian transport. SEM images of both glacial and interglacial samples revealed that dust particles (Fig. 5) are more abundant in the fraction of the insoluble residue of the glacial samples. Point chemical analyses, and morphology revealed the presence of predominantly quartz grains and, more rarely, dolomite in the samples. The quartz grains show the abraded, rounded surfaces, whilst the dolomite grains show euhedral habit in situ growth.

\section{$\mathrm{X}$-ray fluorescence}

Confidence in the AvaaTech XRF scanner results for individual elements is assured by directly calibrating the scan data with data from a conventional XRF instrument permitting a robust, quantitative 

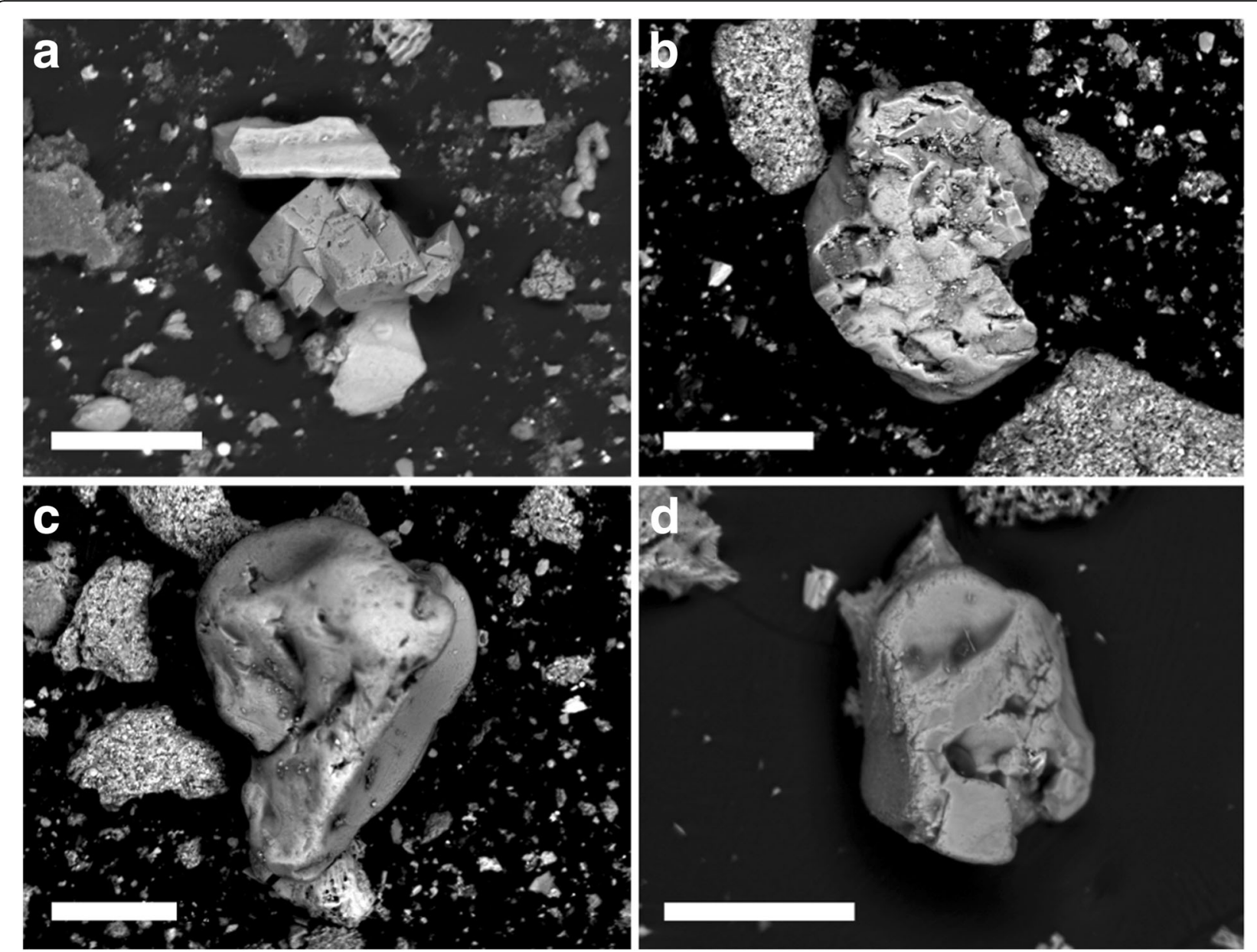

Fig. 5 Dust grains in various samples uncovered by scanning electron microscopy. SEM images showing selected dolomite (a) and quartz (b-d) grains. The dust particles are recognised because of their abraded surfaces; scale bar $=100 \mu \mathrm{m}$

assessment of the scanning results for individual elements. We recognise that the lithogenic content of the sediments at Site U1467 is low (several \%) which may affect the reliability of the AvaaTech XRF scanning output. The carbonate platform and pelagic carbonate production is high in tropical settings diluting the lithogenic component and producing low concentrations of the terrigenous elements $(\mathrm{Fe}, \mathrm{K}, \mathrm{Al}, \mathrm{Si}, \mathrm{Mg}$ and $\mathrm{Ti}$ ). As the conventional XRF technique used with the Philips PW2404 spectrometer is formally calibrated using internationally recognised standards, and the samples homogenised, the resulting data are more robust. Therefore, we measured elements in samples from a selected interval to calculate correlation coefficients between the two datasets based on scanning counts.

We measured 67 samples from Cores 359-U1467C$4 \mathrm{H}$ to $-6 \mathrm{H}$ on both XRF instruments. These samples cover the full range of lithologies observed at Site U1467, from almost pure carbonate to clay-rich carbonates. The pellets were first measured on the conventional XRF instrument in Edinburgh and the same pellets were sent to College Station in Texas and measured on the AvaaTech XRF core scanner. This procedure facilitates calculation of regression lines and correlation coefficients for the individual elements. Correlation coefficients range from about 0.2 to 0.9 . $\mathrm{Ti}$ shows the lowest value of about 0.2 , whereas $\mathrm{Fe}$ has a value of about 0.80 , and $\mathrm{Al}$ has a value of 0.85 . $\mathrm{K}$ and $\mathrm{Si}$ have the highest values of about 0.9. These results suggest that on the one hand AvaaTech XRF core scanner results for $\mathrm{Ti}$ are not robust, but on the other hand they seem reasonably reliable for $\mathrm{Fe}$ and $\mathrm{Al}$, and they seem very robust for $\mathrm{K}$ and $\mathrm{Si}$. The reason for unreliability of $\mathrm{Ti}$ measured by the AvaaTech core scanner is the low concentrations of $\mathrm{Ti}$ in the sediments. Although core scanner results seem reasonably robust for $\mathrm{Fe}, \mathrm{Al}, \mathrm{K}$ and $\mathrm{Si}$, it is not clear at this point whether the core scanner reliably measures amplitude of change for individual elements. Water 
content, grain size, porosity and other unknown factors may influence the element intensities (Kido et al. 2006; Koshikawa et al. 2003; Tjallingii et al. 2007). All data measured by the XRF instruments at Texas A\&M University and the University of Edinburgh are listed in Additional file 1: Table S1.

Element intensities are plotted against composite depth in Fig. 6. The Fe, K, Si and Ti records all show cyclical changes throughout the record. The cyclical changes are related to primary Milankovitch frequencies given the general sedimentation rate of $3 \mathrm{~cm} / \mathrm{kyr}$ of the investigated interval based on biostratigraphy (Betzler et al. 2017b). As such, the cyclical changes relate to the glacial-interglacial cycles dominating the climate system in the last $2 \mathrm{Myr}$, with high and low values representing sediment deposition during glacial and interglacial periods, respectively. Marine isotopic stages (MIS) can be readily assigned to the individual cycles in the depth domain (Fig. 6). All element intensity records show a conspicuous long-term upwards trend from, on average, low to high values, and from small to large changes in amplitude. Conspicuous increases in the element intensity records occur during MIS 20, 22 and 24 within the MPT interval. This is particularly evident in the Fe intensity curve. The highest values of all element intensities can be found in the younger glacial periods of MIS 2, 6 and 8. The interglacial values of element intensities records are low throughout the sequence. The lowest values can be found in the early part of the record, particularly MIS 31, 49, 55, 57, 61, 63 and 73, although these values are not much lower than some of the minimal

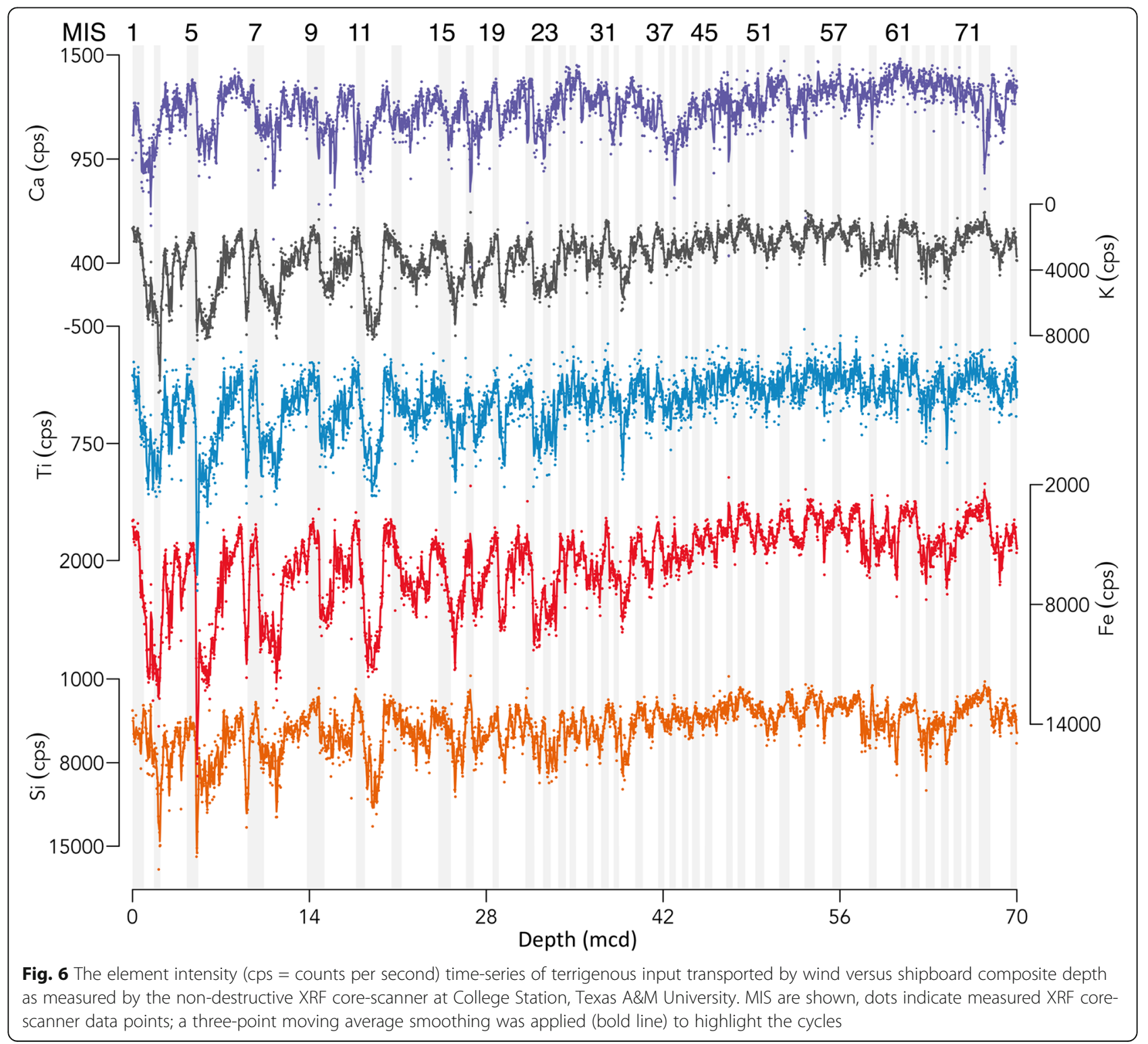


values in specific interglacial intervals such as in MIS 7 and 9 in the younger part of the record.

To evaluate the AvaaTech XRF core scanner results in terms of lithogenic variations, we aim to present element ratios to remove dilution effects of carbonate (Shimmield and Mowbray 1991; Schneider et al. 1997). Commonly, element/Al ratios are used to remove the effect of variability in carbonate content reflecting biogenic production of marine sediments. Although this seems a straightforward procedure, previous studies (e.g. Kido et al. 2006; Koshikawa et al. 2003; Tjallingii et al. 2007) have shown that water content, grain size, porosity and other unknown factors may influence the element intensities. Light elements, such as $\mathrm{Al}$, are more susceptible to these effects compared to the heavier elements, which are affected to a lesser extent and thus more reliable. To evaluate whether element/Al ratios as measured by the core scanner are affected by these factors, we compared the element/Al core scanner results with the conventional XRF results (not shown here) in the depth domain. The two data sets show large disparities, indicating that $\mathrm{Al}$ is heavily affected by water content and other factors of the sediment. Therefore, element/Al is not suitable for the purpose of this study.

We tested the validity of the $\mathrm{Fe} / \mathrm{K}$ aridity proxy by plotting the conventional XRF and 'wet' and 'dry' scanner results in the depth domain of a piece of the record (Fig. 7), whereby the same pellets were used for the conventional XRF and core scanner. To mitigate the effects of slight sediment displacement within the core as a result of sampling of discrete samples and scanning, that were done on the working half and archive half, respectively, we used a three-point running average through the data. The 'wet' and 'dry' $\mathrm{Fe} / \mathrm{K}$ profiles are very similar, implying that water content and grain size changes do not substantially affect the record. The conventional XRF results also show a similar profile. The orbital cycles are noticeable, although some disparities occur. Overall, we conclude that the measurements of $\mathrm{Fe} / \mathrm{K}$ are not perfect but reasonably reliable. Therefore, we apply the $\mathrm{Fe} / \mathrm{K}$ ratio to the entire sediment record representing two million years.

\section{Chronology}

The AvaaTech XRF-based scanning records of element intensity and $\mathrm{Fe} / \mathrm{K}$ show the presence of orbital cyclicity in element concentrations and lithogenic particle composition. We use the $\mathrm{Fe}$ intensity and $\mathrm{Fe} / \mathrm{K}$ records for tuning to insolation cycles, in order to generate an age model for the sequence. All marine isotope stages from MIS 1-73 can be recognised (Fig. 8), but instead of correlating the $\mathrm{Fe}$ intensity and $\mathrm{Fe} / \mathrm{K}$ cycles with the benthic stable isotope stack (LR04), which is based on a compilation of benthic $\delta^{18} \mathrm{O}$ records from multiple sites (Lisiecki and Raymo 2005), the Fe intensity and Fe/K records were directly tuned to the precession parameter of orbital variability (Laskar et al. 2004). Significantly, when the $\mathrm{Ca} / \mathrm{K}$ (carbonate productivity versus lithogenic input) is compared with the corresponding Fe/K curve, the same temporal relationship with insolation emerges (Fig. 8). Direct tuning to precession means that no inference can be made regarding climate and precession, but it allows for the investigation of longer periodicities of eccentricity and obliquity. This tuning method is based on the assumption that aridity in the source areas respond more readily to insolation, although may have an influence from northern hemisphere climate (Clemens et al. 1991). The value of this approach is that it is independent of the LR04 record. It also removes any age offset assumption of the LR04 ice model to insolation forcing. The Fe/K record displays orbital-driven cycles in tandem with the Fe intensity record. The highest amplitude of change of the cycles is in the early part of the record prior to the MPT.

The Fe intensity and $\mathrm{Fe} / \mathrm{K}$ records were smoothed using a three-point moving average. Cycles related to precession are visually pervasive throughout the record. These cycles were directly tuned to the precessional component of the $65^{\circ} \mathrm{N} 21$ st June insolation curve using the La2004 orbital solution (Fig. 8; Laskar et al. 2004). We tied the $\mathrm{Fe}$ intensity minima and $\mathrm{Fe} / \mathrm{K}$ maxima to precession minima (insolation maxima) with zero phase lag using Analyseries 2.0.8 software (Paillard et al. 1996). All tie-lines are given in Additional file 2: Table S2 and the age model, composite depth (mcd) and element intensity values are given in Additional file 3: Table S3. Some studies have used a more local low-latitude insolation curve; however, as both are calculated on 21st of June, the insolation peaks and troughs occur simultaneously. Thus, the age model is not affected by the choice of the different insolation latitude. To illustrate this point, we plot both the 21st June insolation records at $65^{\circ}$ and $10^{\circ} \mathrm{N}$ alongside the Fe intensity and Fe/K records in Fig. 8.

To assess the validity of the precession-based chronology, we have filtered the orbital components of the $\mathrm{Fe} /$ $\mathrm{K}$ time series (Fig. 9). In addition to the precessional component, which should include the artefact of the tuning approach, the filtered components of obliquity and eccentricity from the $\mathrm{Fe} / \mathrm{K}$ record are shown in comparison to the respective obliquity and eccentricity components of the $65^{\circ} \mathrm{N}$ 21st June insolation curve using the La2004 orbital solution (Laskar et al. 2004). This confirmation of the presence of eccentricity and obliquity periods in the filtered respective records confirms our approach of using precession cycles to obtain a chronology of the record. It is particularly the pervasive presence of the obliquity cycles that lends increased confidence in our age model. 


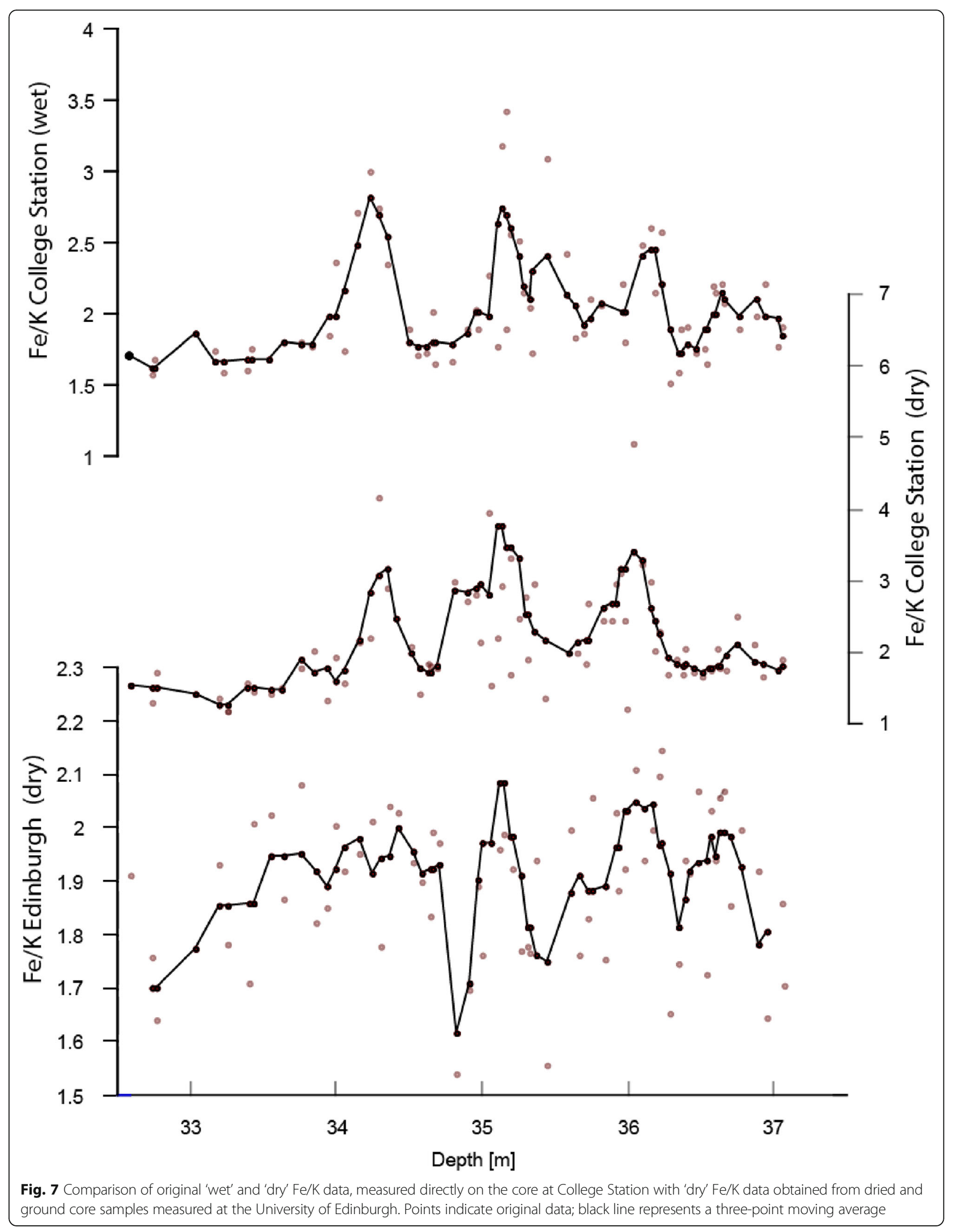




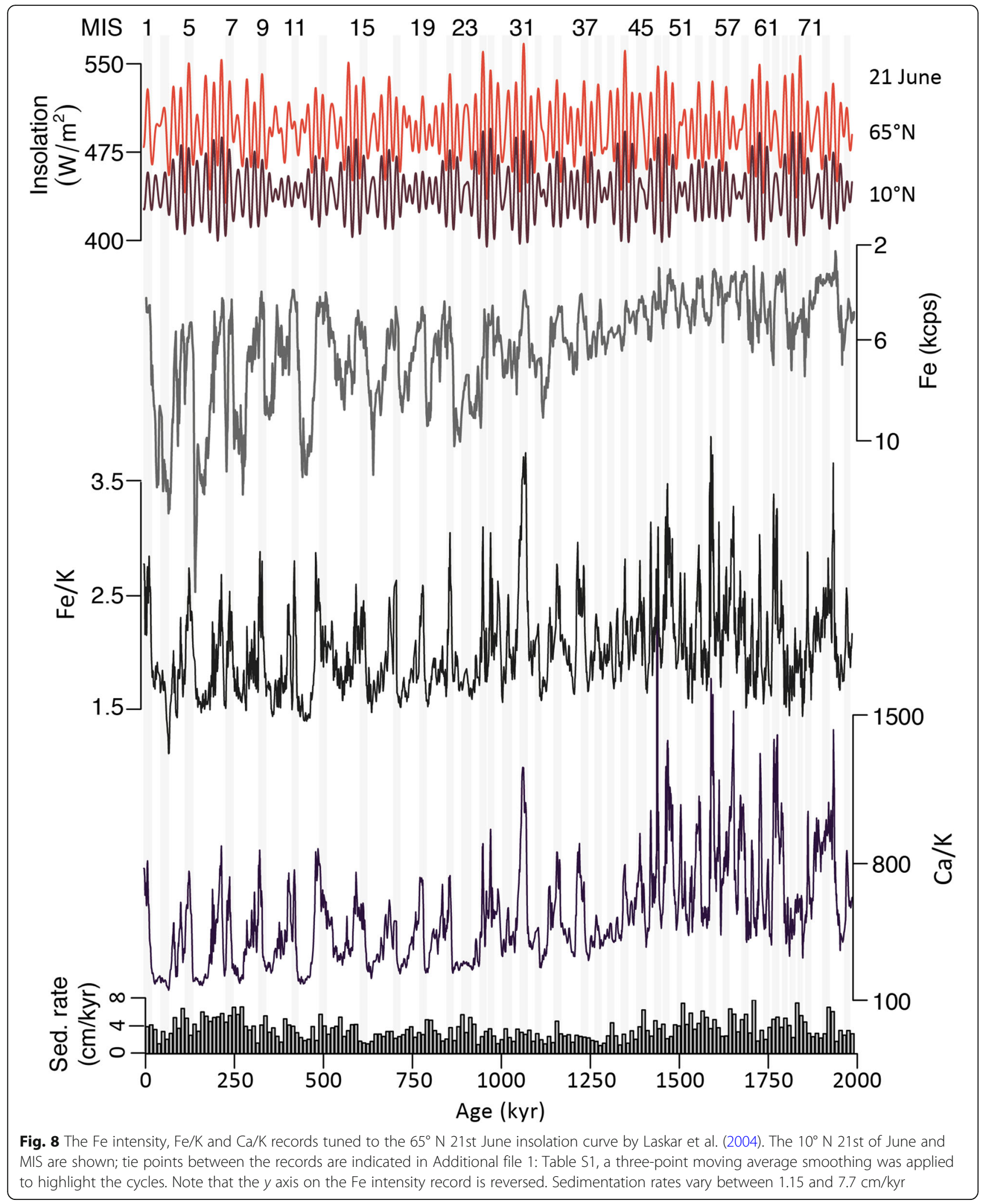




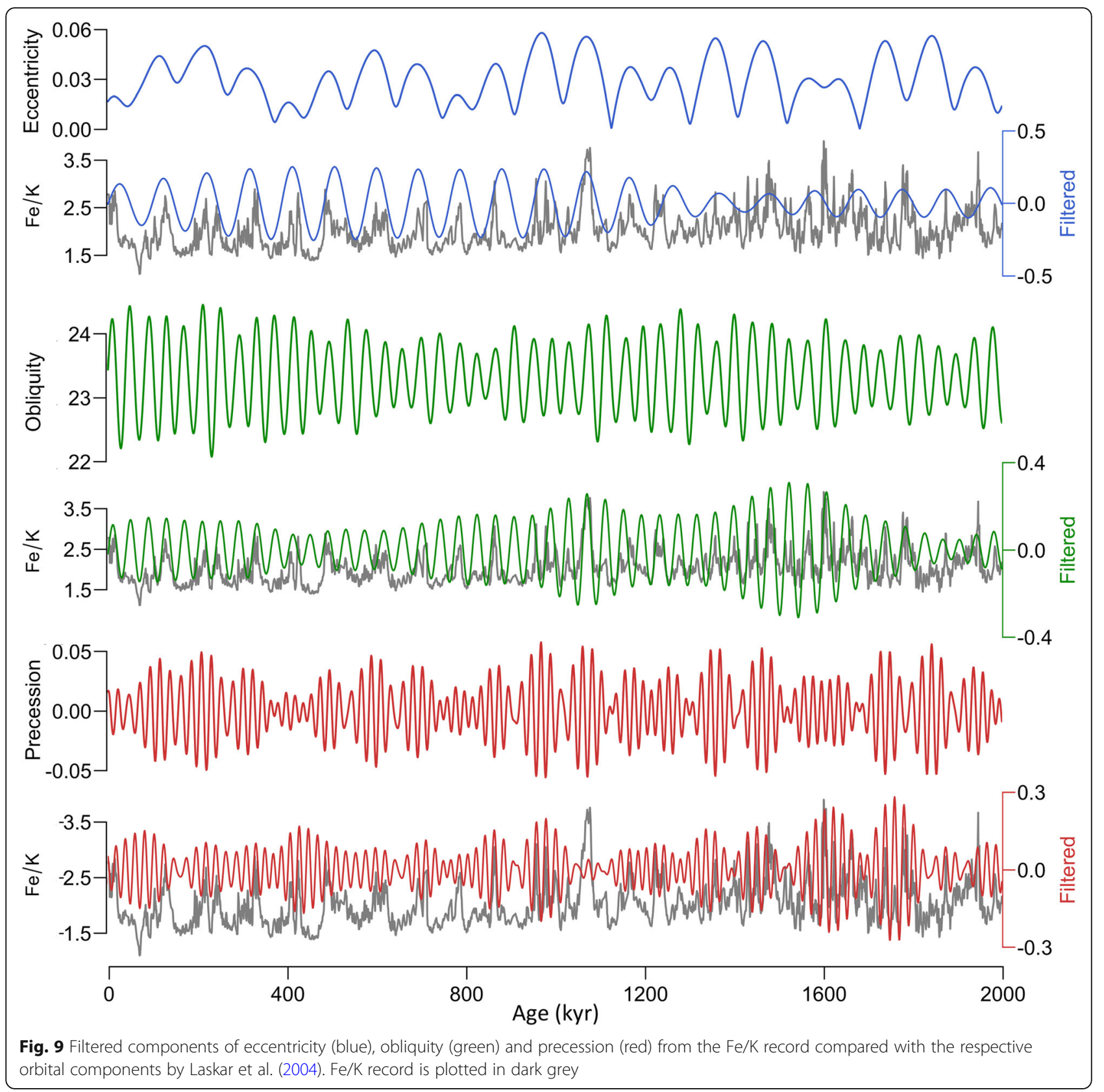

\section{Spectral and wavelet analyses of the Fe intensity, Fe/K and LR04 records}

Spectral (Fig. 10) and wavelet (Fig. 11) analyses of the $\mathrm{Fe}$ intensity, $\mathrm{Fe} / \mathrm{K}$ and LR04 records show pervasive presence of the primary orbital cycles. The Fe/K spectral and wavelet results display distinct power in the precession frequency band, although this may have been somewhat artificially induced because of the age modelling approach. This is particularly evident in the one to two million year time-window (Fig. 11). The $\mathrm{Fe} / \mathrm{K}$ spectral and wavelet results also show occurrence of tilt throughout the record, affirming the age modelling approach. Power of tilt is less strong in the $\mathrm{Fe} / \mathrm{K}$ record than in the LR04 record. An important feature of the wavelet diagrams is the presence of strong eccentricity $(100 \mathrm{kyr})$ in the $0-1.25$ million year interval and occurrence of faint eccentricity like (spectral power broadly ranging around $130 \mathrm{kyr}$ ) in the 1.25-2 million year interval, resulting in a distinct switch in the lower frequency band that is eccentricity related around 1.25 million years ago: spectral power of eccentricity-like cycles $(\sim 130 \mathrm{kyr})$ diminishes and proper eccentricity cycles (100 kyr) emerge. 


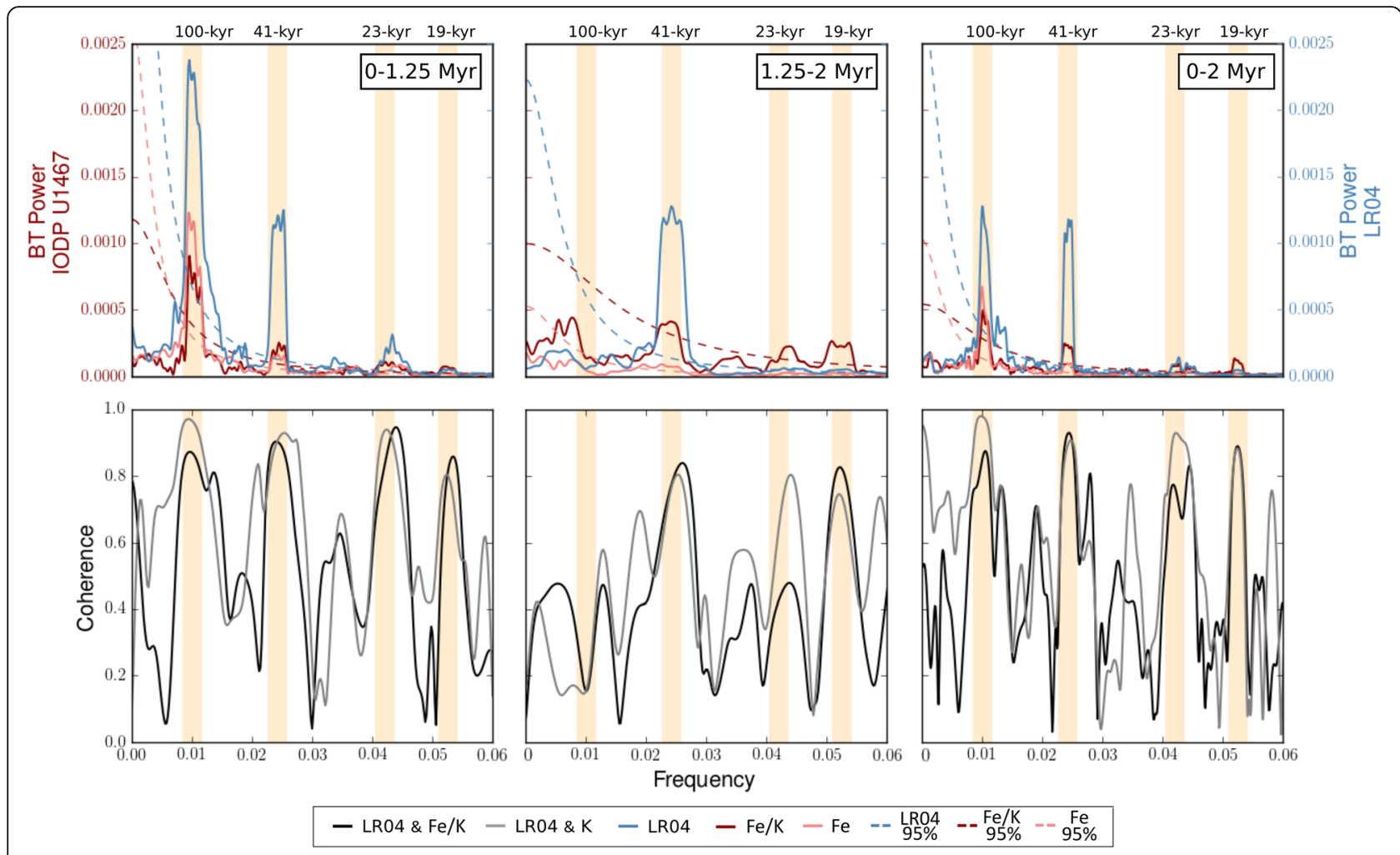

Fig. 10 Spectral analysis results using the Fe intensity (light red), Fe/K (dark red) and LR04 benthic stable oxygen isotope stack (blue) records. Also, coherences between Fe intensity and LR04 (grey) and Fe/K and LR04 (black) are shown. Dashed lines indicate 95\% confidence levels (see legend)

\section{Discussion}

IODP Expedition 359 drilled a continuous sedimentary archive in the Maldives, available for monsoonal research (Betzler et al. 2017a, b). We set out to use variability in the lithogenic component of the sediments to study wet-dry cycles in the Indian-Asian source areas in the Plio-Pleistocene. We use the $\mathrm{Fe} / \mathrm{K}$ as an aridity proxy indicating cyclical changes between humid and dry conditions on the Indian-Asian landmass.

\section{Moisture changes in source areas of the Indian-Asian landmass}

Variations in the composition of lithogenic material in marine sediments are used to infer source area weathering, representing changes between humid and dry conditions driven by summer and winter monsoon activity, respectively. We follow the assumptions by previous studies that strong precipitation over the continent during summer monsoons increases flux of fluvial material, whereas aeolian dust flux increases during winter monsoon (Govin et al. 2012; Simon et al. 2016; Ziegler et al. 2013). On long-term time-scales, changes in the hydrological cycle, and subsequently changes in the annual monsoon activity, is driven by orbitally forced insolation variability (Clemens et al. 1991). Therefore, we use the assumption that $\mathrm{Fe} / \mathrm{K}$ ratios are an indicator of long-term variability of fluvial versus aeolian flux, where Fe represents chemical weathering of soils and $\mathrm{K}$ represents the mechanical weathering. Thus, we conclude that high $\mathrm{Fe} / \mathrm{K}$ ratios are indicative of periods of increased chemical weathering (humid climate), while low $\mathrm{Fe} / \mathrm{K}$ ratios indicate increased mechanical weathering (arid climate). At present, we do not precisely know which minerals host the Fe component. However, in the tropical humid region of southern India, relatively high temperatures and high precipitation (summer monsoon) favour chemical weathering of bedrocks resulting in heavily lateritized bedrocks. These weathered soils are enriched in Fe oxides and clays which are transported as suspended matter by rivers to the India Ocean. Thus, we relate the high $\mathrm{Fe} / \mathrm{K}$ ratios in the Maldives record to a relative shift towards more chemical weathering and fluvial activity in India during warm and wet interglacial periods. This is further supported by clay mineral distribution along the Indian continental margin. Kolla et al. (1981) documented high percentages of smectite clays around the margin of India, which were supplied by rivers that drain the soils developed on the Deccan trap basalts. The content of smectite along the western margin generally decreases from north to south, but the percentage of smectite significantly increases again near the southern tip of India, which is a result of westward 


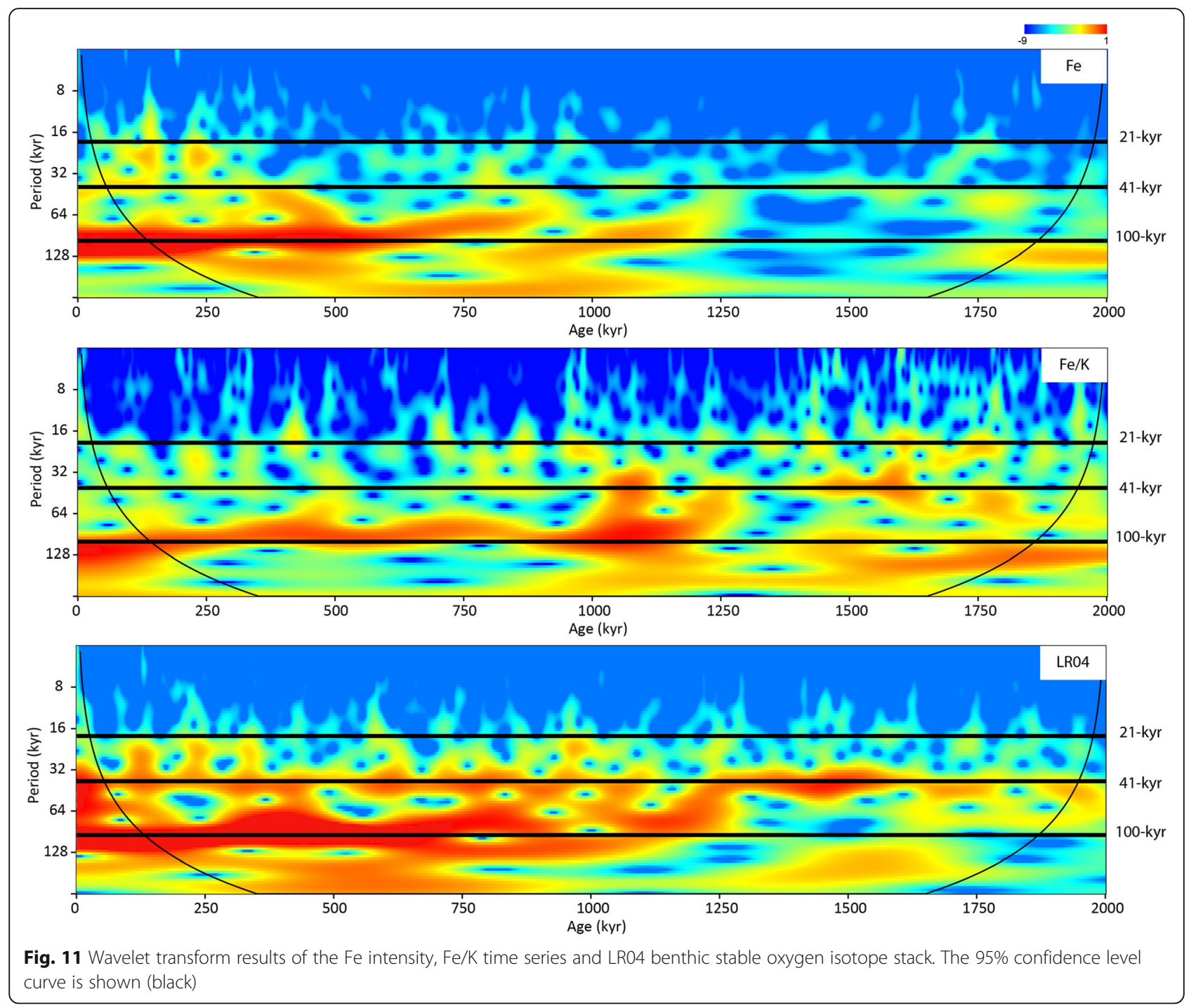

currents carrying smectite from the Bay of Bengal (Kolla et al. 1981; Wyrtki 1973). The Maldives as a sediment trap receive these smectite clays (and by inference other $\mathrm{Fe}$ bearing minerals) because of low salinity surface currents flowing from the Bay of Bengal in winter (Kolla et al. 1981). Future work is needed to investigate and confirm all possible sources of $\mathrm{Fe}$ in the study site; however, that is currently beyond the scope of this paper.

In low-latitude dry regions (deserts), low temperatures and low precipitation during winter monsoon promote mechanical weathering of bedrocks, resulting in K-rich illite and feldspars (Kolla et al. 1981). Thus, we relate the low $\mathrm{Fe} / \mathrm{K}$ ratios in the Maldives record to a relative shift towards more mechanical weathering and aeolian activity in further afield desert areas during cold and dry glacial periods. The most likely illite sources during these cold and windy periods are of aeolian origin coming from the surrounding arid regions further afield, such as the Thar desert and Arabian Peninsula. Also, the Indus River was much reduced during the glacial periods, and suspended material was unlikely to reach the Maldives.

We selected a small number of samples (7) to investigate mineral content of the lithogenic fraction using the X-ray diffraction method across the sediment record. The analyses showed substantial percentages of minerals of the smectite group showing that Indian-derived clays were deposited in the Maldives. Montmorillonite (Fe) of the smectite group minerals is most abundant (up to 15\%) and importantly shows an inversed occurrence with illite (K) in the samples, reflecting weight percentages of Indian-derived (fluvial) versus desert-derived (wind) clay minerals. We concede that XRD analysis should be carried out across a number of cycles to verify 
shifting mineral assemblages, but this is currently beyond the scope of this paper.

We conclude that $\mathrm{Fe} / \mathrm{K}$ ratios reflect changes in monsoonal climates resulting in aeolian versus fluvial transport modes from the source areas to the ocean. High Fe/K ratios in an interval of sediments indicate that increased chemical weathering occurred during the wet summer monsoon season, coeval with heating of the continent, and that rivers transported abundant suspended Fe to the ocean. Aeolian transport of this Fe-rich material is unlikely due to the elevated moisture promoting vegetation growth and suppressing wind erosion. The alluvial flux of $\mathrm{Fe}$ to the Maldives will be further enhanced during wet periods as not only will the sources from chemical weathering be increased but also the higher precipitation will further reduce the salinity of the surface ocean currents bringing the sediment to the Maldives. Increased buoyancy of the surface ocean will inhibit mixing and sediment loss into the deep ocean along the transport pathways. Conversely, low $\mathrm{Fe} / \mathrm{K}$ ratios in an interval of sediment indicate that increased mechanical weathering occurred during the dry winter monsoon concomitant with cooling of the continent in the source areas, and that strong winter winds transported abundant quartz (see Fig. 5), illite and K-rich feldspars to the ocean. We expected subtle changes in the $\mathrm{Fe} / \mathrm{K}$ ratios of the lithogenic fraction in the Site U1467 sediments, because only a small fraction of fluvial-derived material arrives at the Maldives. In contrast, majority of the lithogenic fraction arrives as dust. We recognise that processes controlling the $\mathrm{Fe} / \mathrm{K}$ are multiple and complex, but ultimately, the amplitude of change in the $\mathrm{Fe} / \mathrm{K}$ record reflects relatively wet (chemical weathering) versus dry (mechanical weathering) conditions linked to the hydrological cycle driven by monsoon activity in various source areas of the adjacent continent or further afield.

We plot the $\mathrm{Fe} / \mathrm{K}$ record together with the deep-sea stable oxygen isotope stack (LR04; Lisiecki and Raymo
2005; Fig. 12). The Fe/ $\mathrm{K}$ cycles correlate to the marine isotopic stages, with high and low values during interglacial and glacial stages, respectively (Fig. 12), reflecting on orbital-driven wet versus dry cycles. The high $\mathrm{Fe} / \mathrm{K}$ values during interglacial periods indicate more humid conditions (intense summer monsoon) and the low values point to drier conditions during the glacial periods (intense winter monsoon). Some of the 'wettest' interglacial periods (MIS 55, 61 and 73) and 'driest' glacial periods (MIS stages 52 to 74 ) occur in the early part of the record prior to the MPT. One of the last distinct 'wet' periods MIS 31 occurs during the MPT. To add confidence in the interpretation of $\mathrm{Fe} / \mathrm{K}$ cycles representing wet-dry cycles in the hinterland, we also plotted the Fe flux record (Fig. 13, Additional file 4: Table S4), which is a firmly established aridity proxy record (Clemens and Prell 1990, 1991). The Fe flux cycles confirm the interpretation of the $\mathrm{Fe} / \mathrm{K}$ record with humid conditions during interglacial periods and dry conditions during glacial periods (Fig. 13).

\section{Two million year record of insolation-driven Indian-Asian hydroclimate}

The Indian-Asian climate is directly controlled by monsoon activities, which are sensitive to regional insolation changes driven by orbital precession, although effects associated with high-latitude climate changes may also play a role. The $\mathrm{Fe} / \mathrm{K}$ cycles at Site U1467 track northern hemisphere summer insolation, reflecting on moisture supply from the Arabian Sea. Sensitivity experiments support the assumption that positive summer rainfall shows a strong relationship with orbital precession (Clemens and Prell 1991). Visual inspection of the $\mathrm{Fe} / \mathrm{K}$ record revealed the glacial-interglacial cycles and precession-driven cycles. On the basis of the presence of distinct precession cycles (particularly during interglacials) and initial age

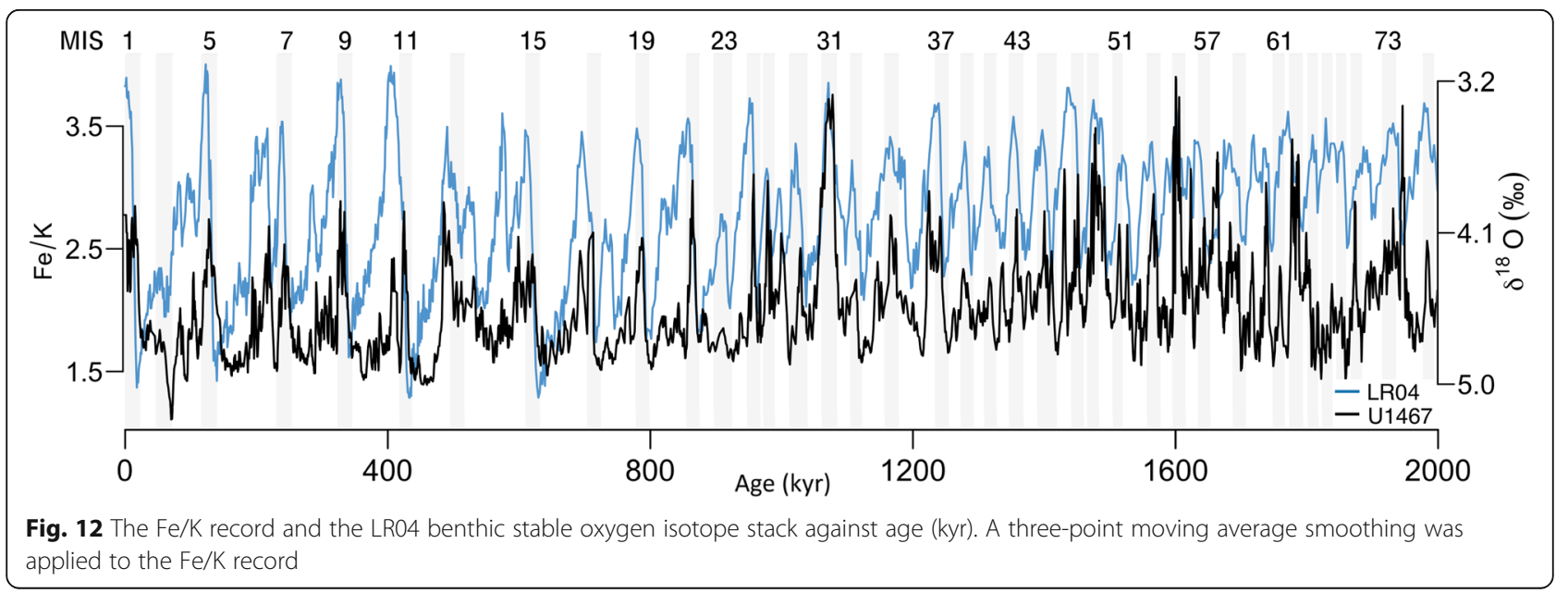




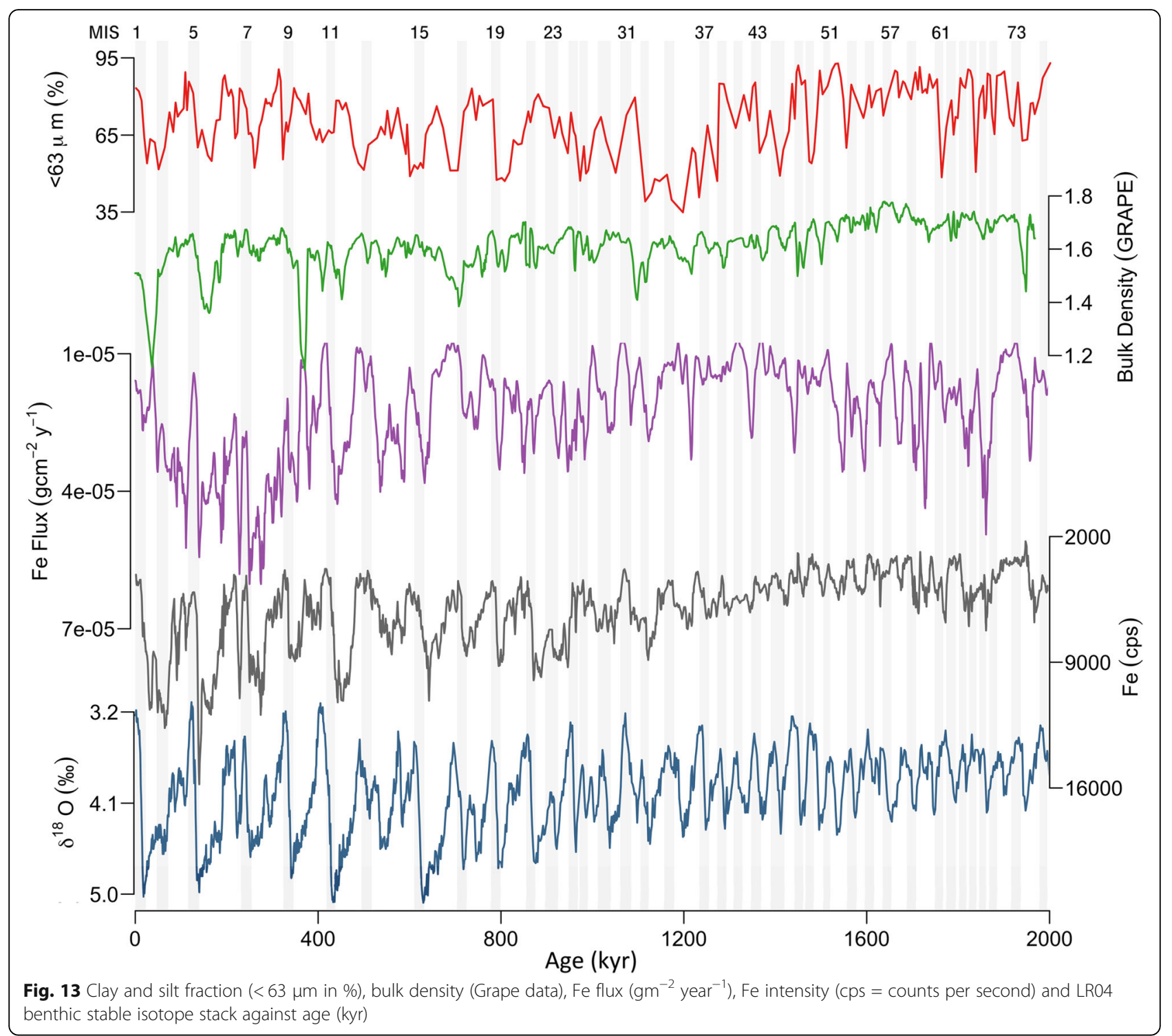

modelling, we tuned the $\mathrm{Fe} / \mathrm{K}$ record to precession. Our approach was to correlate maximum Fe/K ratios to insolation peaks (precession minima) and minimum $\mathrm{Fe} / \mathrm{K}$ ratios to insolation lows (precession maxima).

The spectral and wavelet analyses diagrams of the $\mathrm{Fe} / \mathrm{K}$ display distinct power in the precession frequency band. It is particularly evident in the 1.25 to 2 million year time-window (Figs. 10 and 11), where spectral power resolves the $23 \mathrm{kyr}$ and the $19 \mathrm{kyr}$ cycles. However, it is important to note that the direct tuning to precession may have induced an artificial precession signal. The presence of tilt (41 kyr cycle) in the spectral analysis throughout the record, on the other hand, confirms our age model approach. Other striking features of the spectral diagrams is the presence of strong eccentricity $(100 \mathrm{kyr})$ in the $0-1.25$ million year interval and occurrence of faint eccentricity (spectral power broadly ranging from 80 to $140 \mathrm{kyr}$ ) in the
1.25-2 million year interval. Wavelet power analysis shows similar orbital frequency features in the $\mathrm{Fe} / \mathrm{K}$ record. The low-frequency eccentricity cycles present prior to the MPT have been previously described by Liu et al. (2008) in the Ocean Drilling Project Site 722 sea surface temperature record, defining them as eccentricity-like cycles likely formed by bundling of two or three obliquity cycles resulting in saw tooth patterns. The same bundling of tilt cycles is observed in the $\mathrm{Fe} / \mathrm{K}$ record prior to the MPT. Liu et al. (2008) postulated that such bundling of tilt cycles was paced by eccentricity. We infer that combined presence of tilt (bundled in saw tooth shapes) and precession (amplified by the 100-kyr-like cycle) is pivotal for understanding orbitally forced low-latitude humidity changes in the pre-MPT period, resulting in extreme monsoon-driven climates. The wettest interglacial periods (MIS stages 31, 55, 61 and 73) and 'driest' glacial periods (MIS stages 52 to 74 ) occur in 


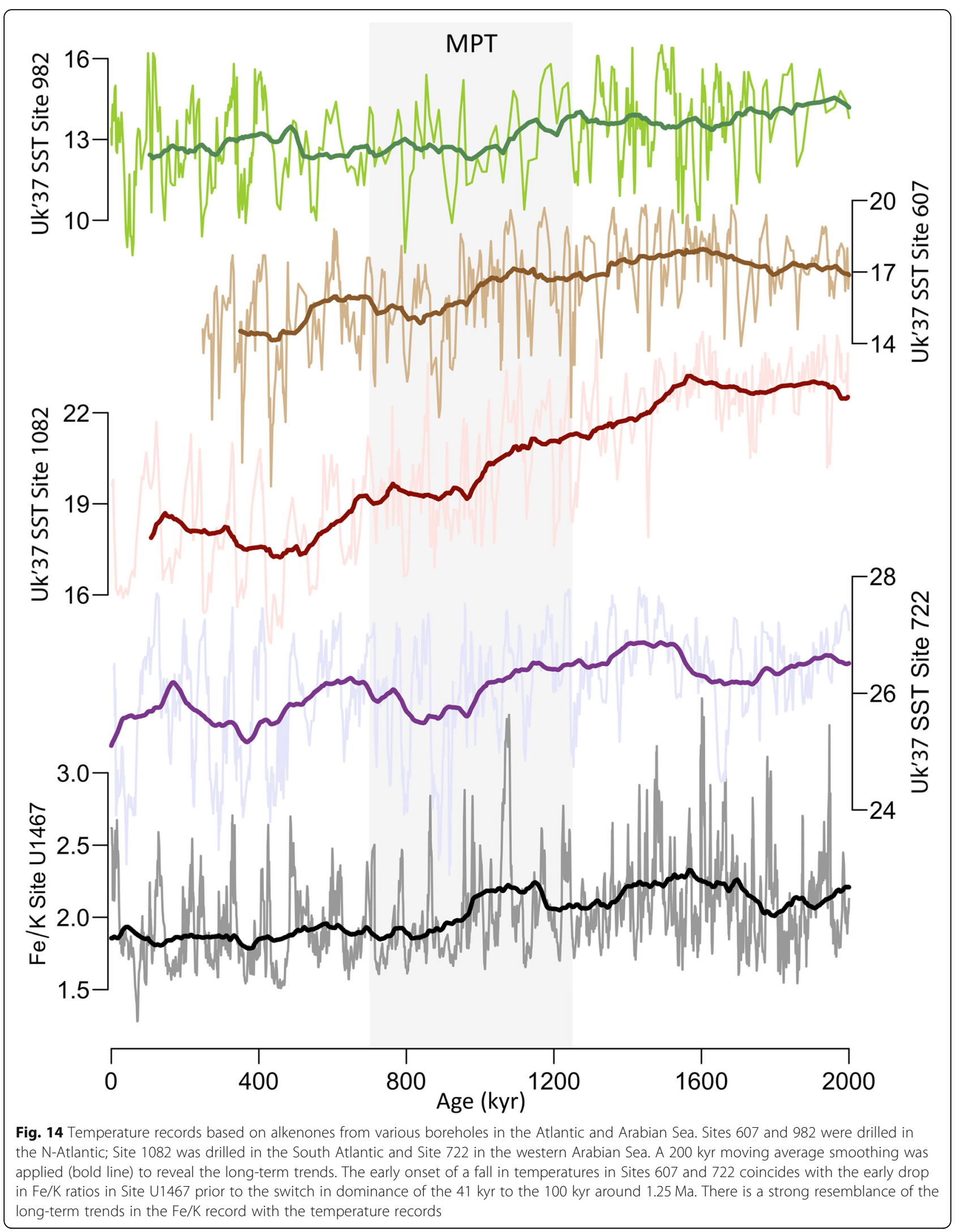


this interval. MIS 31 is the maximum peak of the $\mathrm{Fe} / \mathrm{K}$ record, likely reflecting minimal dust and maximum fluvial-derived inputs in the sediments of the Maldives coinciding with the highest peak of the total insolation profile in the last two million years.

\section{The link between the $\mathrm{Fe} / \mathrm{K}$ aridity record and the global ice volume record}

The $\mathrm{Fe} / \mathrm{K}$ record shows a significant coherence with the LR04 benthic stable oxygen isotope record of mainly global ice volume over all primary orbital periodicities (Lisiecki and Raymo 2005; Fig. 12). This suggests that low-latitude aridity and global ice volume changes are linked, reflecting on common orbital forcing principles of climate. However, the wavelet power analyses of the Fe/K and LR04 benthic stable oxygen isotope records show a notable disparity (Fig. 11) concerning influence of eccentricity forcing. While the eccentricity-like $(130 \mathrm{kyr})$ cycles are distinct in the pre-MPT period, revealed by considerable power in the wavelet power analysis, there are no such eccentricity-like cycles (or they are very faint) in the LR04 record. Notably, power on the eccentricity $(100 \mathrm{kyr})$ cycles in both the Fe/K and LR04 records emerges around 1.25 million years, suggesting a strengthening climate link between the two areas. The low-latitude monsoon system likely responded to the high-latitude ice sheet histories, or alternatively, both areas responded to a common unknown climate driver emerging at the time. Comparison of the long-term average change in the Fe/K record to the Arabian Sea Site 722 and various Atlantic sea surface temperature records reveals a long-term shift towards drier conditions in the low latitudes concomitant with sea surface temperature falls in the Arabian Sea and high latitudes across MIS stage 22-24, further suggesting a strengthening climate link between low and high latitudes across the MPT (Fig. 14).

Lisiecki and Raymo (2005) used a simple ice model based on 21 June insolation at $65^{\circ} \mathrm{N}$ with a set lag to insolation allowing for ice sheet response time. This phase lag is adjusted during the late Pliocence to early Pleistocene from 5 to $15 \mathrm{kyr}$ from 3.0 to 1.5 , to represent the increasing ice mass during this interval. In contrast, the aridity record of the Maldives is directly tuned to insolation to represent the highly sensitive response of Indian-Asian hydroclimate to insolation changes. As a result of the different tuning approaches, our records of the Maldives lead the LR04 benthic stacked record (Fig. 12). The consistency of this phase lead should serve as a test of the robustness of the tuning approaches of either the LR04 stack or our record. The phase lag is evidently the case during deglaciations throughout the record.

\section{Conclusions}

The Maldives sedimentary archive contains a valuable lithogenic input record reflecting on terrestrial climate changes in the source areas of the Indian-Asian landmass or from further afield. The $\mathrm{Fe} / \mathrm{K}$ aridity record shows orbitally forced cycles reflecting on changes in the relative importance of aeolian (stronger winter monsoon) during dry glacial periods versus fluvial supply (stronger summer monsoon) during humid interglacial periods. The chronology is based on precessional cycles visually present in the $\mathrm{Fe} / \mathrm{K}$ record, where $\mathrm{Fe} / \mathrm{K}$ maxima correlate to precession minima (insolation maxima) with zero phase lag. The value of this approach results in an age model independent from the LR04 record.

Wavelet and spectral analyses of the Fe/K record show increased dominance of the 100-kyr cycles throughout the record across the Mid Pleistocene Transition (MPT) in concert with the benthic foraminiferal oxygen isotopic $\delta^{18} \mathrm{O}$ data (LR04 record). The emergence of $100 \mathrm{kyr}$ cycles in both the LR04 and the Fe/K records since the MPT suggests strengthening of a climate link between the low and high latitudes during this period of major climate transition. In contrast to the LR04 record, the $\mathrm{Fe} / \mathrm{K}$ profile displays 100 -kyr-like cycles around the $130 \mathrm{kyr}$ frequency band, prior to the MPT, in the interval 1.25 to 2 million years ago. The influence (power) of the 100-kyr-like cycles weakens towards the MPT. These 100-kyr-like cycles likely form by bundling of three obliquity cycles. The development of the 100-kyr-like cycle between two and one million years indicates that low latitude Indian-Asian climate variability reflects on increased tilt sensitivity to regional eccentricity insolation changes (pacing tilt cycles) prior to the MPT, resulting in large amplitude changes of the $\mathrm{Fe} / \mathrm{K}$ record. As a result, both 'wettest' interglacial periods (MIS stages 31, 55, 61 and 73) and 'driest' glacial periods (MIS stages 52 to 74 ) occur in this interval.

\section{Additional files}

Additional file 1: Table S1. X-ray fluorescence comparison between conventional XRF (University of Edinburgh) and XRF core-scanner (Texas A\&M University). (XLSX 12 kb)

Additional file 2: Table S2. Age model tie-lines. (XLSX $13 \mathrm{~kb}$ ) Additional file 3: Table S3. Composite splice (mcd), age (kyr), element intensities (cps). (XLSX 169 kb)

Additional file 4: Table S4. Age (kyr), sedimentation rate, bulk density (Grape) and Fe flux. (XLSX $155 \mathrm{~kb}$ )

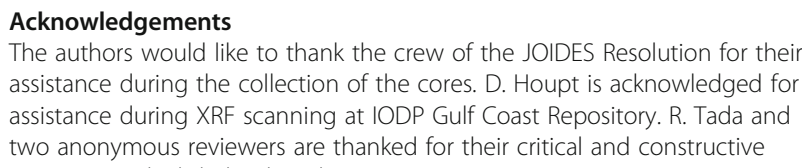
assistance during the collection of the cores. D. Houpt is acknowledged for assistance during XRF scanning at IODP Gulf Coast Repository. R. Tada and two anonymous reviewers are thanked for their critical and constructive comments which helped to sharpen our concept.

Funding

DK acknowledges support by the Natural Environment Research Council (NERC 3148), funding support for conventional XRF, core scanning and technical assistance. MAG acknowledges support provided by the 
Portuguese National Science and Technology Foundation (SFRH/BPD/ 96960/2013, PTDC/MAR-PRO/3396/2014 and UID/Multi/04326/2013), funding support for core scanning.

\section{Availability of data and materials}

The datasets generated and/or analyzed during the current study are available in the Pangaea repository (https://doi.pangaea.de/10.1594/ PANGAEA.897951)

\section{Authors' contributions}

TK led the writing of the manuscript, contributed to figures and statistical analysis. SJAJ contributed to analysing the data and several figures. ESL contributed to sample preparation for conventional XRF scanning and statistical analysis. NO contributed to conventional XRF scanning. ALT contributed to statistical analysis and design of several figures. CB served as Co-Chief on the Maldives Leg, contributed to shipboard handling and description of cores, contributed to core scanning. GPB served as Co-Chief on the Maldives Leg, contributed to shipboard handling and description of cores, contributed to core scanning. CAAZ served as IODP manager on the Maldives Leg, contributed to shipboard handling and description of cores, contributed to core scanning. MAG contributed to shipboard handling of cores and micropaleontology, contributed to core scanning. OMB contributed to shipboard handling and description of cores. CLB contributed to shipboard handling of cores and chemistry. JAG contributed to shipboard handling and physical properties of cores. SHa contributed to shipboard handling of cores and physical properties of cores. SHo contributed to handling of cores and physical properties. ALHM contributed to shipboard handling and description of cores. MI contributed to shipboard handling of cores and chemistry. LG contributed to shipboard handling of cores and magnetostratigraphy, contributed to core scanning. LL contributed to shipboard handling of cores and magnetostratigraphy. JCL contributed to shipboard handling and description of cores, contributed to core scanning. TL contributed to shipboard handling of cores and geophysics. BNN contributed to shipboard handling and description of cores. MN contributed to shipboard handling and description of cores. $\mathrm{KN}$ contributed to shipboard handling of cores and micropaleontology. LMP contributed to shipboard handling of cores and micropaleontology. SDP contributed to shipboard handling of cores and micropaleontology. JJGR contributed to shipboard handling and description of cores, contributed to core scanning. JR contributed to shipboard handling and description of cores, contributed to core scanning. ALS contributed to shipboard handling of cores and core logging. CRS contributed to shipboard handling and description of cores, contributed to core scanning. XS contributed to shipboard handling of cores and micropaleontology. PKS contributed to shipboard handling of cores and chemistry. JDW contributed to shipboard handling cores, correlated the boreholes, and contributed to core scanning. ZY contributed to shipboard handling and description of cores. JRY contributed to shipboard handling cores and micropaleontology. SL contributed to shore based grain size analyses. SS contributed to core scanning. AR contributed to core scanning. SS contributed to core scanning. IC contributed to core scanning. SY contributed to core scanning. DK contributed to shipboard handling of cores, micropaleontology and core scanning. All authors contributed to writing of the manuscript.

\section{Competing interests}

The authors declare that they have no competing interest.

\section{Publisher's Note}

Springer Nature remains neutral with regard to jurisdictional claims in published maps and institutional affiliations.

\section{Author details}

'School of GeoSciences, Grant Institute, University of Edinburgh, The King's Buildings, West Mains Road, Edinburgh EH9 3JW, UK. Institute of Geology, CEN, University of Hamburg, Bundesstrasse 55, 20146 Hamburg, Germany. ${ }^{3}$ Department of Marine Geosciences, Rosenstiel School of Marine \& Atmospheric Science, University of Miami, Miami, FL 33149, USA. ${ }^{4}$ International Ocean Discovery Program, Texas A\&M University, Discovery Drive, College Station, TX 77845, USA. Instituto Português do Mar e da
Atmosfera (IPMA), Divisão de Geologia e Georecursos Marinhos, Rua Alfredo Magalhães Ramalhoi 6, 1495-006 Lisboa, and Centro de Ciências do Mar (CCMAR), Universidade do Algarve, Faro, Portugal. ${ }^{6}$ Dr. Moses Strauss Department of Marine Geosciences, The Leon H. Charney School of Marine Sciences, University of Haifa, 31905 Carmel, Israel. ${ }^{7}$ Department of Geosciences, Princeton University, Guyot Hall, Princeton, NJ 08544, USA. ${ }^{8}$ Department of Geological Sciences, California State University Bakersfield, 9001 Stockdale Highway, Bakersfield, CA 93311, USA. ${ }^{9}$ Ecole Nationale Supérieure de Géologie, Université de Lorraine, 2 rue du Doyen Marcel Roubault, 54501 Vandoeuvre-les-Nancy, France. ${ }^{10}$ Petroleum and Marine Research Division, Korea Institute of Geoscience \& Mineral Resoursces (KIGAM), Gwahang-no 124, Yuseong-gu, Daejeon 305-350, South Korea. ${ }^{11}$ Graduate School of Natural Science and Technology, Okayama University, 3-1-1 Tsushima-naka, Okayama 700-8530, Japan. ${ }^{12}$ Instituto Oceanográfico da Universidade de São Paulo, Praça do Oceanográfico, 191, São Paulo, SP 05508-120, Brazil. ${ }^{13}$ Department of Pure and Applied Science, Università di Urbino, "Carlo Bò" Via S. Chiara 27, I-61029 Urbino, Italy. ${ }^{14}$ Department of Geology and Geophysics, Texas A\&M University, College Station, TX 77843-3115, USA. ${ }^{15}$ Geological Oceanography Division, CSIR-National Institute of Oceanography, Dona Paula, Goa 403004, India. ${ }^{16}$ Department of Environmental Engineering for Symbiosis, Soka University, 1-236 Tangi-cyo, Hachioji-shi, Tokyo 192-0003, Japan. ${ }^{17}$ Graduate School of Science and Engineering, Yamagata University, 1-4-12 Kojirakawa-machi, Yamagata 990-8560, Japan. ${ }^{18}$ Environmental Science and Policy Department, George Mason University, David King Hall Rm 3005, MSN 5F2, University Drive, Fairfax, VA 22030-4444, USA. ${ }^{19}$ Department of Geosciences, Geological Engineering Faculty - Universitas Padjadjaran, Jl. Raya Bandung Sumedang KM 21, Jatinangor 45363, Indonesia. ${ }^{20}$ College of Petroleum Engineering and Geosciences, King Fahd University of Petroleum and Minerals, Dhahran 3126, Saudi Arabia. ${ }^{21}$ Lamont-Doherty Earth Observatory, Columbia University, Borehole Bldg. 61 Route 9W, Palisades, NY 10964, USA. ${ }^{22}$ Earth and Environmental Sciences, University of Technology Queensland, R-Block 317, 2 George Street, Brisbane, QLD 4001, Australia. ${ }^{23}$ Department of Marine Geology, First Institute of Oceanography (FIO) State Oceanic Administration (SOA), \#6 Xian Xia Ling Road, Qingdao, Shandong 266061, People's Republic of China. ${ }^{24}$ Department of Geological Sciences, Rutgers, The State University of New Jersey, 610 Taylor Road, Piscataway, NJ 08854-8066, USA. ${ }^{25}$ Key Laboratory of Marginal Sea Geology, South China Sea Institute of Oceanology, Chinese Academy of Sciences, West Xingang Road, Guangzhou 510301, People's Republic of China. ${ }^{26}$ Department of Earth Sciences, University College London, Gower Street, London WC1E 6BT, UK.

${ }^{27}$ Department of GeoSciences, Université de Fribourg, Ch. du Musée 6 1700, Fribourg, Switzerland.

Received: 3 October 2017 Accepted: 8 November 2018 Published online: 18 December 2018

\section{References}

Aerosol Optical Thickness (1 month - Terra/MODIS) | NASA. In: Aerosol Optical Thickness (1 month - Terra/MODIS) | NASA. https://neo.sci.gsfc.nasa.gov/view. php?datasetld=MODAL2_M_AER_OD\&year=201

Berger W, Jansen E (1994) In: Johannessen O, Muench R, Overland J (eds) he Polar Oceans and their Role in Shaping the Global EnvironmentMidPleistocene climate shift-The Nansen connection. AGU, Washington D.C., pp 295-311

Betzler C, Eberli G, Alvarez Zarikian C, Alonso-García M, Bialik O, Blättler C, Guo J, Haffen S, Horozal S, Inoue M, Jovane L, Kroon D, Lanci L, Laya J, Ling Hui Mee A, Lüdmann T, Nakakuni M, Nath B, Niino K, Petruny L, Pratiwi S, Reijmer J, Reolid J, Slagle A, Sloss C, Su X, Swart P, Wright J, Yao Z, Young J (2017a) Expedition 359 summary. Proceedings of the International Ocean Discovery Program. https://doi.org/10.14379/iodp.proc.359.101.2017

Betzler C, Eberli G, Alvarez Zarikian C, Alonso-García M, Bialik O, Blättler C, Guo J, Haffen S, Horozal S, Inoue M, Jovane L, Kroon D, Lanci L, Laya J, Ling Hui Mee A, Lüdmann T, Nakakuni M, Nath B, Niino K, Petruny L, Pratiwi S, Reijmer J, Reolid J, Slagle A, Sloss C, Su X, Swart P, Wright J, Yao Z, Young J (2017b) Site U1467. Proceedings of the International Ocean Discovery Program. https://doi.org/10.14379/iodp.proc.359.101.2017

Betzler C, Eberli G, Kroon D, Wright J, Swart P, Nath B, Alvarez-Zarikian C, AlonsoGarcía M, Bialik O, Blättler C, Guo J, Haffen S, Horozal S, Inoue M, Jovane L, Lanci L, Laya J, Mee A, Lüdmann T, Nakakuni M, Niino K, Petruny L, Pratiwi S, Reijmer J, Reolid J, Slagle A, Sloss C, Su X, Yao Z, Young J (2016) The abrupt 
onset of the modern south Asian monsoon winds. Sci Rep. https://doi.org/ 10.1038/srep29838

Clemens S, Murray D, Prell W (1996) Nonstationary phase of the Plio-Pleistocene Asian monsoon. Science 274:943-948. https://doi.org/10.1126/science.274. 5289.943

Clemens S, Prell W (1990) Late Pleistocene variability of Arabian Sea summer monsoon winds and continental aridity: Eolian records from the lithogenic component of deep-sea sediments. Paleoceanography 5:109-145. https:// doi.org/10.1029/pa005i002p00109

Clemens S, Prell W (1991) One million year record of summer monsoon winds and continental aridity from the Owen ridge (site 722), northwest Arabian Sea. In: Prell W, Niitsuma N et al (eds) Scientific results. Proceedings of the ocean drilling program, vol 117, pp 365-388

Clemens S, Prell W, Murray D, Shimmield G, Weedon G (1991) Forcing mechanisms of the Indian Ocean monsoon. Nature 353:720-725. https:// doi.org/10.1038/353720a0

deMenocal P, Ortiz J, Guilderson T, Adkins J, Sarnthein M, Baker L, Yarusinsky M (2000) Abrupt onset and termination of the African humid period. Quat Sci Rev 19:347-361. https://doi.org/10.1016/s0277-3791(99)00081-5

Elderfield H, Ferretti P, Greaves M, Crowhurst S, McCave I, Hodell D, Piotrowski A (2012) Evolution of ocean temperature and ice volume through the midPleistocene climate transition. Science 337:704-709. https://doi.org/10.1126/ science.1221294

Govin A, Holzwarth U, Heslop D, Ford Keeling L, Zabel M, Mulitza S, Collins J, Chiessi C (2012) Distribution of major elements in Atlantic surface sediments $\left(36^{\circ} \mathrm{N}-49^{\circ}\right.$ S): imprint of terrigenous input and continental weathering. Geochem Geophys Geosyst 13:Q01013. https://doi.org/10.1029/2011gc003785

Govindaraju K (1994) Compilation of working values and sample description for 383 geostandards. Geostand Geoanal Res 18:1-158. https://doi.org/10 1111/j.1751-908x.1994.tb00526.x

Grant K, Rohling E, Westerhold T, Zabel M, Heslop D, Konijnendijk T, Lourens L (2017) A 3 million year index for north African humidity/aridity and the implication of potential pan-African humid periods. Quat Sci Rev 171:100118. https://doi.org/10.1016/j.quascirev.2017.07.005

Hammer $\varnothing$, Harper D, Ryan P (2001) Past: paleontological statistics software package for education and data analysis. Palaeontol Electron

Head M, Gibbard P (2015) Early-middle Pleistocene transitions: linking terrestrial and marine realms. Quat Int 389:7-46. https:/doi.org/10.1016/j.quaint.2015.09.042

Herbert T, Peterson L, Lawrence K, Liu Z (2010) Tropical ocean temperatures over the past 3.5 million years. Science 328:1530-1534. https://doi.org/10.1126/ science. 1185435

Ivanochko T, Ganeshram R, Brummer G, Ganssen G, Jung S, Moreton S, Kroon D (2005) Variations in tropical convection as an amplifier of global climate change at the millennial scale. Earth Planet Sci Lett 235:302-314. https://doi.org/10.1016/j.epsl.2005.04.002

Kido Y, Koshikawa T, Tada R (2006) Rapid and quantitative major element analysis method for wet fine-grained sediments using an XRF microscanner. Mar Geol 229:209-225. https://doi.org/10.1016/j.margeo.2006.03.002

Kolla V, Kostecki J, Robinson F, Biscaye P, Ray P (1981) Distributions and origins of clay minerals and quartz in surface sediments of the Arabian Sea. SEPM Journal of Sedimentary Research. https://doi.org/10.1306/ 212f7cd9-2b24-11d7-8648000102c1865d

Koshikawa T, Kido Y, Tada R (2003) High-resolution rapid elemental analysis using an XRF microscanner. J Sediment Res 73:824-829. https://doi.org/10.1306/ 020503730824

Laskar J, Robutel P, Joutel F, Gastineau M, Correia A, Levrard B (2004) A long-term numerical solution for the insolation quantities of the earth. Astronomy \& Astrophysics 428:261-285. https://doi.org/10.1051/0004-6361:20041335

Leuschner D, Sirocko F (2003) Orbital insolation forcing of the Indian monsoon-a motor for global climate changes? Palaeogeogr Palaeoclimatol Palaeoecol 197:83-95. https://doi.org/10.1016/s0031-0182(03)00387-0

Lisiecki L, Raymo M (2005) A Pliocene-Pleistocene stack of 57 globally distributed benthic $\delta 180$ records. Paleoceanography 20:1-17. https://doi.org/10.1029/ 2004pa001071

Liu Z, Cleaveland LC, Herbert TD (2008) Early onset and origin of 100-kyr cycles in Pleistocene tropical SST records. Earth Planetary Sci Lett 265(3-4):703-715.

Lyle M, Backman J (2013) Data report: calibration of XRF-estimated CaCO3 along the Site U1338 splice. In Pälike H, Lyle M, Nishi H, Raffi I, Gamage K, Klaus A and the Expedition 320/321 Scientists, Proc. IODP, 320/321: Tokyo (Integrated Ocean Drilling Program Management International, Inc.). https://doi.org/10. 2204/iodp.proc.320321.205.2013.
Maslin M, Brierley C (2015) The role of orbital forcing in the early middle Pleistocene transition. Quat Int 389:47-55. https://doi.org/10.1016/j.quaint. 2015.01.047

McDonald W (1938) Atlas of climatic charts of the oceans. U.S. Govt. Print. Off, Washington

Middleton NJ (1986) Dust storms in the Middle East. J Arid Environ 10:83-96

Milliman JD, Quraishee GS, Beg MAA (1984) Sediment discharge from the Indus River to the ocean: past, present and future. In: Haq B, Milliman J. Marine geology and oceanography of Arabian Sea and coastal Pakistan. Van Nostrand Reinhold, New York, p 1986

Mudelsee M, Stattegger K (1997) Exploring the structure of the mid-Pleistocene revolution with advanced methods of time-series analysis. Geol Rundsch 86: 499-511. https://doi.org/10.1007/s005310050157

Mulitza S, Prange M, Stuut J, Zabel M, von Dobeneck T, Itambi A, Nizou J, Schulz M, Wefer G (2008) Sahel megadroughts triggered by glacial slowdowns of Atlantic meridional overturning. Paleoceanography 23:PA4206. https://doi. org/10.1029/2008pa001637

Nair R, Ittekkot V, Manganini S, Ramaswamy V, Haake B, Degens E, Desai B, Honjo $S$ (1989) Increased particle flux to the deep ocean related to monsoons. Nature 338:749-751. https://doi.org/10.1038/338749a0

Paillard D, Labeyrie L, Yiou P (1996) Macintosh program performs time-series analysis. Eos, Transactions American Geophysical Union 77:379-379. https:// doi.org/10.1029/96eo00259

Prospero JM (1981) Arid regions as sources of mineral aerosols in the marine atmosphere. In: Péwé TL (ed) Desert dust-origin, characteristics, and effects on man, vol 186. Spec. Pap.-Geol. Soc Am, pp 71-86

Reynolds RC (1963) Matrix corrections in trace element analysis by X-ray fluorescence: estimation of the mass absorption coefficient by Compton scattering. Am Mineral 48:1133-1143

Rodrigues T, Alonso-García M, Hodell D, Rufino M, Naughton F, Grimalt J, Voelker A, Abrantes F (2017) A 1-ma record of sea surface temperature and extreme cooling events in the North Atlantic: a perspective from the Iberian margin. Quat Sci Rev 172:118-130. https://doi.org/10.1016/j.quascirev.2017.07.004

Schneider R, Price B, Müller P, Kroon D, Alexander I (1997) Monsoon related variations in Zaire (Congo) sediment load and influence of fluvial silicate supply on marine productivity in the east equatorial Atlantic during the last 200,000 years. Paleoceanography 12:463-481. https://doi.org/10.1029/96pa03640

Shimmield G, Mowbray SR (1991) The inorganic geochemical record of the northwest Arabian Sea: a history of productivity variation over the last 400 k.y. from sites 722 and 724, Proceedings of the Ocean Drilling Program, Scientific Results, vol 117, pp 409-429

Simon MH, Ziegler M, Bosmans J, Barker S, Reason CJC, Hall IR (2016) Eastern South African hydroclimate over the past 270,000 years. Sci Rep 5(1).

Tjallingii R, Röhl U, Kölling M, Bickert T (2007) Influence of the water content on $X$-ray fluorescence core-scanning measurements in soft marine sediments. Geochem Geophys Geosyst 8:Q02004. https://doi.org/10.1029/2006gc001393

Wyrtki K (1973) Physical oceanography of the Indian Ocean. In: Zeitschel (ed) The biology of the Indian Ocean. Springer-Verlag, New York

Yu Y, Kalashnikova OV, Garay MJ, Lee H, Notaro M (2018) Identification and Characterization of Dust Source Regions Across North Africa and the Middle East Using MISR Satellite Observations. Geophysical Research Letters 45 (13): 6690-6701.

Ziegler M, Simon M, Hall I, Barker S, Stringer C, Zahn R (2013) Development of middle stone age innovation linked to rapid climate change. Nat Commun. https://doi.org/10.1038/ncomms2897 